\title{
La basílica devastada: el bombardeo de la catedral de Reims y la identidad nacional del arte gótico
}

\author{
María Bendito* \\ UN MANUAL CONTRA LA DESTRUCCIÓN BÉLICA
}

El 5 de diciembre de 2016, Mechtild Rössler, directora de la División del Patrimonio de la Organización de Naciones Unidas para la Educación, la Ciencia y la Cultura (Unesco), presentó un manual de actuación militar destinado a la protección del patrimonio en situación de conflicto armado. ${ }^{1}$ Amparada por el International Institute of Humanitarian Law, ${ }^{2}$ la publicación se presentó en el marco de la jornada Patrimoine menacé: à la recherche de nouveaux paradigmes. Sauver le patrimoine à travers le dialogue, con la presencia y aportaciones de representantes de diversas organizaciones internacionales. Entre ellos se encontraban Irina Bokova, directora general de la Unesco, y Abulfas Garayev, ministro de Cultura y Turismo de la República de Azerbaiyán, país patrocinador de la publicación. ${ }^{3}$

El manual, que se ofreció como un avance en cuanto a instrucciones de protección y salvamento de bienes culturales, supone un paso más en las medidas relativas al patrimonio tomadas a partir de la segunda mitad del siglo xx —nos referimos al Primer Protocolo de La Haya de $1954^{4}$

1. O'Keefe, R.; Péron, C.; Musayev, T.; Ferrari, G., Protection of cultural property: military manual. París: Unesco, 2016, disponible en http://unesdoc.unesco.org/images/oo24/o02466/246633e.pdf [fecha de consulta: 3 de enero de 2017]. Entre los autores destaca Roger O'Keefe, director adjunto del Lauterpacht Centre for International Law, centro de investigación sobre el desarrollo de leyes internacionales asociado a la Facultad de Derecho de la University of Cambridge. Algunas de sus anteriores publicaciones en esta misma línea han sido: O'KeEFE, R., National implementation of the penal provisions of the Chapter 4 of the Second Protocol of 26 March 1999 to the Hague Convention of 1954 for the Protection of Cultural Property in the Event of Armed Conflict, investigación presentada el 29 de marzo de 2002 para la Unesco y registrada homónimamente en el archivo de la Unesco de París, o The Protection of cultural property in armed conflict. Cambridge: Cambridge University Press, 2006.

2. Con sede en la ciudad de San Remo, esta organización independiente se ha forjado una gran reputación como centro de investigación y desarrollo de cuestiones acerca de la ley humanitaria. El organismo lleva trabajando en actividades de cooperación entre organismos homólogos —instituciones militares, centros de investigación, organizaciones internacionales, etc.- desde el año de su fundación, en 1970. En cuanto al manual militar, el instituto figura como lugar de publicación junto con la sede de la Unesco en París.

3. Como expresa Irina Bokova en las primeras páginas del manual, la publicación ha podido realizarse gracias a la colaboración entre todos los organismos. O’Keefe, R.; Péron, C.; MusaYev, T.; FerRari, G., Protection of cultural property..., pág. XIV.

4. Entre el 21 de abril y el 14 de mayo de 1954, se celebró en La Haya la primera Conferencia Intergubernamental sobre la Protección de los Bienes Culturales en caso de conflicto armado, convocada por la Unesco. Esta convención surgió a raíz de la masiva destrucción que provocó la Segunda Guerra Mundial y tuvo como resultado el primer pacto internacional para la protección de bienes muebles e inmuebles — monumentos arquitectónicos, artísticos, históricos, sitios arqueológicos, obras de arte, manuscritos, libros, objetos de interés artístico, histórico o arqueológico, colecciones científicas y otras piezas de valor independientemente de su origen o propiedad-. Esta convención dio lugar al conocido Protocolo de La Haya, cuyas resoluciones, enfocadas en la prevención de la exportación de bienes culturales en territorio ocupado, fueron redac-

* Esta investigación se enmarca en los proyectos de investigación financiados por el Ministerio de Economía y Competitividad: ACAF/ART IV «Cartografías analíticas, críticas y selectivas del entorno artístico y monumental del área mediterránea en la edad moderna» (HAR201566579-P), y CCAV/ ART II «Cartografía crítica del arte y la visualidad en la era global: nuevas metodologías, conceptos y enfoques analíticos» (HAR201343122-P). 
y al Segundo Protocolo de La Haya de $1999-,{ }^{5}$ así como de las derivadas de los recientes conflictos bélicos en Irak, Líbano y Siria, entre otros. Aunque el objetivo fundamental del manual es sistematizar, mejorar y regular las condiciones y acciones necesarias para asegurar la supervivencia del patrimonio, también tiene en cuenta que el deterioro o destrucción de este no solo es, o puede ser, consecuencia de acciones bélicas, sino también el resultado de procesos de su instrumentalización ideológica, que llegan a falsear su identidad y significado simbólico. ${ }^{6}$

Estos dos procesos, en el marco histórico de las dos grandes guerras mundiales de la primera mitad del siglo xx, son los que analizamos en el presente artículo. La incidencia recíproca entre guerra y arte - daños causados en el patrimonio artístico—, por un lado, y la reivindicación nacional del patrimonio como arma o instrumento político e ideológico, por otro, nos lleva a plantear cuestiones tales como: la diversificación en el entendimiento de los hechos y circunstancias históricas según las diferentes ideologías presentes en los conflictos -luchas intelectuales acerca de la propiedad y origen de algunas obras-, los procesos de reconciliación y construcción de nuevas identidades al finalizar estos periodos bélicos - conformación de un supuesto Estado europeo a través de propuestas culturales conciliadoras-, la multiplicidad de concepciones artísticas como respuesta a esa conformación y la consecuente diversificación metodológica en el campo de la historia del arte.

\section{El MARTIRIO DE LA CATEDRAL DE REIMS}

A lo largo de la historia, especialmente desde que cayeron sus murallas y la técnica militar superó los límites del cuerpo a cuerpo, los núcleos urbanos han sufrido intensamente los estragos de las contiendas armadas, convirtiéndose en verdaderos campos de destrucción patrimonial. Monumentos que en circunstancias normales mostrarían diferentes discursos artísticos e históricos - entre ellos el de argumentar la identidad nacional de una ciudad o una nación-, pasan a ser, a causa de la guerra, ruinas simbólicas, tal como sucedió en el periodo de la Primera Guerra Mundial con la ciudad de Reims y, especialmente, con su catedral (ilustración 1).

El 3 de septiembre de 1914 las tropas alemanas entraron en Reims. Al día siguiente, atacaron el territorio situado entre la catedral y la Porte de París, construcción dieciochesca que hacía las funciones de arancel y que quedaba al suroeste del monumento. Notre-Dame estaba aún intacta a pesar de que durante el asedio los obuses la habían cercado simbólicamente, cayendo en la rue du Trésor, alineada a la fachada principal y orientada al oeste, la rue Robert-de-Coucy, que recorría el lado norte, la rue du Cloître, tras el ábside, y la place du Parvis, espacio abierto en su frente. El 12 de septiembre las tropas alemanas fueron derrotadas por las de la alianza

\footnotetext{
tadas en París por el Consejo Jurídico de la Unesco. Véase «Protocolo», Acta Final de la Conferencia Intergubernamental sobre la Protección de los Bienes Culturales en caso de conflicto armado, La Haya, 1954. París: Unesco, págs. 69-77.

5. La destrucción de bienes culturales durante las décadas de 1980 y 1990 puso de relieve la necesidad de actualizar el primer protocolo de 1954. Este proceso de renovación, iniciado en 1991, condujo a la celebración de una nueva convención el 26 de marzo de 1999. Véase Segundo Protocolo de la Convención de La Haya de 1954 para la Protección de los Bienes Culturales en caso de Conflicto Armado, La Haya, 26 de marzo de 1999. Durante la redacción de este trabajo, la página web de la Unesco modificó el acceso a los protocolos de 1954 y 1999, sintetizándolos en un solo documento accesible en inglés y francés bajo el título Textos fundamentales, disponible en http://www.unesco.org/new/es/culture/themes/armed-conflictand-heritage/resources-and-publications/\#c287991 [fecha de consulta: 23 de enero de 2017].

6. "The inclusion of the three terms [theft, pillage, misappropriation] where the last alone would have sufficed -theft and pillage both being forms of misappropriation - was for no more than the avoidance of doubt. It was intended to ensure that all kinds of wrongful taking of cultural property, however named, were covered»: O'KEEFE, R.; PÉRON, C.; MUSAYEV, T.; FERRARI, G., «Misappropiation and vandalism of cultural property», en: idem, Protection of cultural property..., pág. 45.
} 
francobritánica en Marne y los franceses reconquistaron la ciudad al día siguiente. Pero la vuelta a la normalidad fue un espejismo. El antiguo lugar de coronación de los reyes ga$\operatorname{los}^{7}$ fue bombardeado - sin razón estratégica militar alguna según los franceses- por el ejército alemán el 19 de septiembre de 1914, convirtiéndola inmediatamente en símbolo del vandalismo enemigo y del profundo dolor de toda Francia. ${ }^{8}$

No así, evidentemente, opinaban los alemanes (ilustración 2) ni otras voces de países supuestamente neutrales. $\mathrm{Al}$ respecto, es de interés resaltar los comentarios aparecidos en la revista Le Correspondant de 1915, que exponen una posible razón militar y estratégica al considerar las torres de la catedral como lugar de observación del enemigo.

C'est avec un profond regret que l'on a appris en Allemagne que la célèbre cathédrale de Reims, un des monuments les plus précieux du Moyen-Âge, n'eut pas été exemptée de servir à des opérations militaires et qu'on y avait placé un poste d'observation, de sorte que l'artillerie allemande se vit dans la dure nécessité de faire fer sur ce poste. Les chefs de l'armée allemande sont les premiers à se réjouir de ce que les dégâts soient moindres que l'on avait pensé. Il serait mal placé de croire que le respect et la vénération des mo-

numents religieux en Allemagne se borne à celle professée par quelques intellectuels et les historiens de l'Art. Cette vénération existe dans toutes les classes de la société allemande et pas moins dans la classe militaire. Une lettre du professeur Richard Hamann, dans le Konigsberger Hartungsche Zeitung, en est un exemple frappant. Ce professeur fit un voyage en France au printemps dernier en compagnie d'un général allemand pour visiter les monuments historiques français et exprimant sa joie d'avoir pu admirer la cathédrale de Reims. Ce général est maintenant devant Reims et écrit le

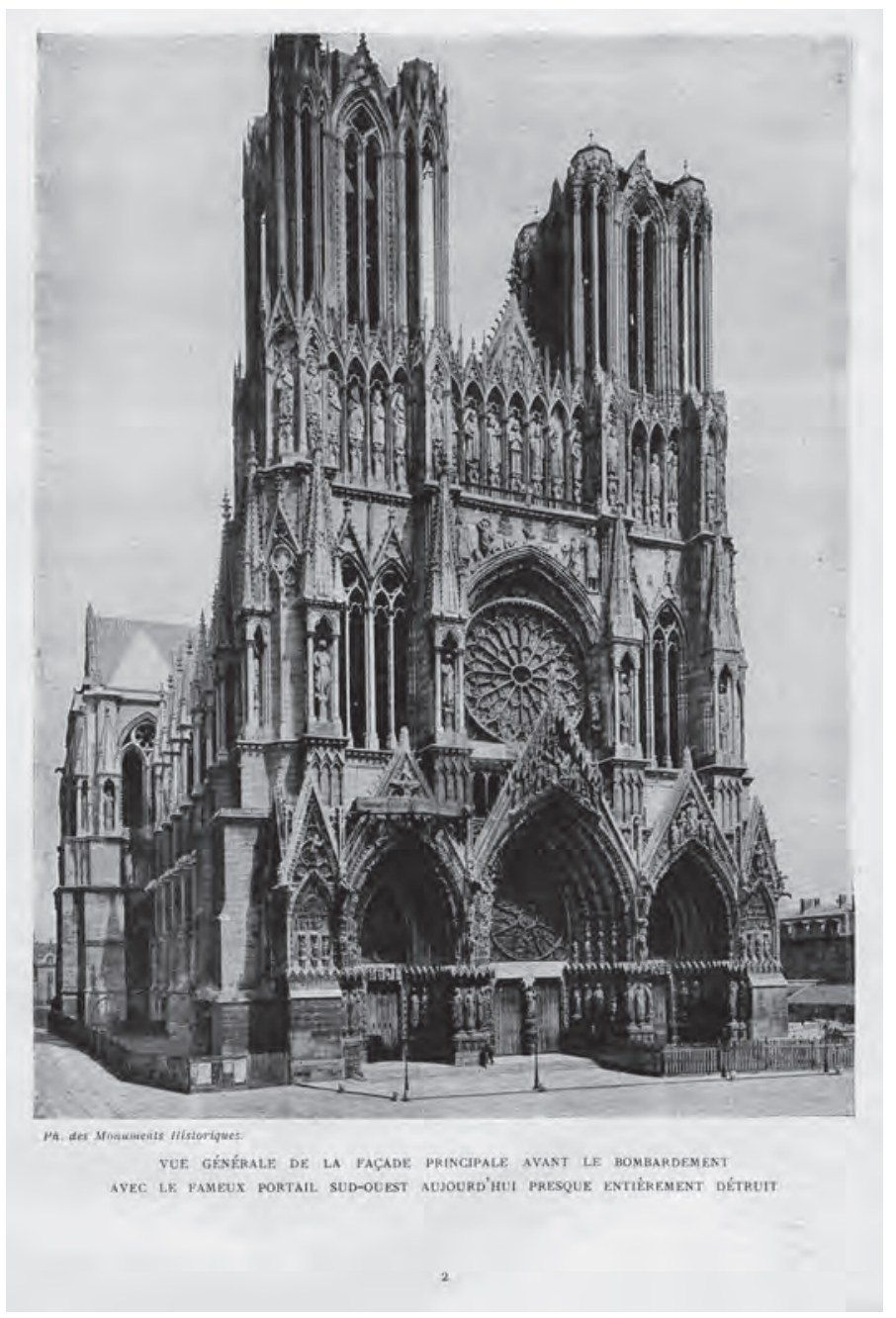

1. «La cathédrale de Reims», L'Art et les Artistes, $\mathrm{xx}$, 1915, pág. 2.

7. La relevancia que se da a la catedral de Reims en este artículo como ejemplo de destrucción artística se justifica por su alto valor simbólico como lugar solemne de coronación de los reyes de Francia desde el siglo XI hasta 1825, año en que fue coronado el penúltimo de los reyes franceses, Carlos X de Francia, quien gobernó entre 1824 y 1830 . El último monarca francés fue Luis Felipe I, de la dinastía Orleans. Su regencia se dilató desde la sustitución del monarca anterior hasta febrero de 1848, cuando firmó su abdicación dando paso a un gobierno provisional que, a su vez, proclamaría la república.

8. Una publicación imprescindible que recoge los acontecimientos previos al bombardeo, el desarrollo del mismo y una enumeración de los daños ocasionados en Reims, además de analizar lo ocurrido en otras regiones, es: Les Allemands destructeurs de cathédrales et de trésors du passé: mémoire relatif aux bombardements de Reims, Arras, Senlis, Louvain, Soissons, etc., accompagné de photographies et de pièces justificatives. París: Hachette, 1915. Igualmente importante es ALEXANDRE, A., Les monuments français détruits par l'Allemagne: enquête entreprise par ordre de M. Albert Dalimier, sous-secrétaire des Beaux-Arts. París: Berger-Levrault, 1918. Mientras se estaba llevando a cabo el proceso de impresión de esta última publicación, se sucedieron nuevos atentados contra el patrimonio francés, hecho que el autor refleja en una nota conmemorativa en la primera página: «Depuis que cet ouvrage est sorti des presses de la Maison Berger-Levrault, de nouveaux attentats ont été commis par les armées allemandes, et les précédents consommés. Parmi les premiers, le bombardement de la cathédrale d'Amiens, et, parmi les seconds, l'incendie féroce et sans but explicable des ruines de Reims». Por otro lado, en cuanto a publicaciones de carácter general sobre la destrucción de patrimonio francés en procesos bélicos es indispensable la aportación de RÉAU, L., Histoire du vandalisme. Les monuments détruits de l'art français, 2 vols. París: Librairie Hachette, 1959. 


\section{PROGLAMATION}

Dans le cas oủ un combat serait livré aujourdhui où très prochainement aux envirous de Rreims on dans la Ville mème. les habitants sont avisés quills devront se tenir absolument calines et n'essayer en ancune manière de prendre part á h bataille. Ils ne doivent tenter d'allaquer ni des soldass isolés ni des détachement de larméc allemande. II est formellement intcrdit deêlever des barricades ou do dépaver des rues de facou à ne pas gèner les monurements des troupes, en un mo de n'entreprendre quoi que ce soil qui putisse être đ'une fagen queleonque uvisible à rimée allemande.

Afin d'assurer saffisamment la sécurité des Troupcs, et afin de répondre du calme de la population de Reims, les personnes nommées ci-après ont élé prises en otages par le commandement général de Tarmée allemande. Ces otages seront pendus à la moindre tentative de désordre. De méme, la rille sera entièrement ou partiellement brülée et les habitants pendus. si me infraction quelconque est commise aax prescriptions précédentes.

Par contre, si li ville se tieat absolument trauquille et calme, les otages et les habitants seront prís sous la sauvegarde de itarmee allemande. Par Ordre de l'autorité Allemande.

Le Maire, D LANGLET.

Neims, le 12 Septembre 1914.

\section{LISTE DES OTAGES}
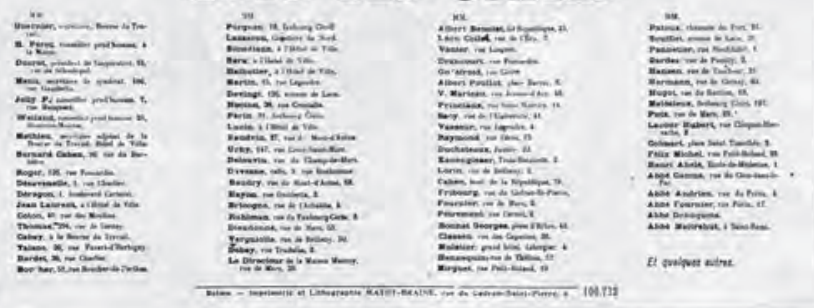

15 septembre à ses amis: «La cathédrale de Reims nous cause bien des soucis, car on s'en sert comme poste d'observation». ${ }^{9}$

De la primitiva construcción, incendiada en 1210, únicamente se conservaba la escultura de una virgen que, situada en el tímpano de uno de los portales del lado norte de la nueva catedral medieval, convertía el edificio en un relicario. La catedral de Notre-Dame de Reims era, pues, un espacio simbólico ataviado con una original y flamante arquitectura gótica, tenida como expresión de la más alta creación humana, del progreso y de la unión gloriosa de la población francesa.

Ante el ataque (ilustración 3), la reacción política gala no se hizo esperar y una comisión ministerial encabezada por Albert Dalimier y Paul Léon, vicesecretario de Estado de Bellas Artes y jefe de la sección de arquitectura respectivamente, visitó Reims y constató infelizmente que la catedral había quedado en estado de ruina.

Sans pouvoir invoquer même l'apparence d'une nécessité militaire, pour le seul plaisir

2. Les Allemands destructeurs de cathédrales et de trésors du passé: mémoire relatifaux bombardements de Reims, Arras, Senlis, Louvain, Soissons, etc., accompagné de photographies et de pièces justificatives. París: Hachette, 1915, pág. 13. de détruire, les troupes allemandes ont soumis la cathédrale de Reims à un bombardement systématique et furieux. A cette heure la fameuse basilique n'est plus qu'un monceau de ruines. Le Gouvernement de la République a le devoir de dénoncer à l'indignation universelle cet acte révoltant de vandalisme qui, en livrant aux flammes un sanctuaire de notre histoire, dérobe à l'humanité une parcelle incomparable de son patrimoine artistique. ${ }^{10}$

La cubierta estaba especialmente dañada. No quedaba testimonio de ella en la nave a excepción de algunas capillas y lo mismo ocurría con la torre norte. ${ }^{11}$ Pero ahí no acabó el de-

9. «La propagande allemande dans les pays neutres. Quelques exemples», Le Correspondant, 258, 1915, págs. 96-97. Tal como afirma Christina Kott (Котт, C., «Histoire de l'art et propagande pendant la Première Guerre mondiale. L'exemple des historiens d'art allemands en France et en Belgique», Revue germanique internationale, 13, 2000, págs. 201-202), una vez terminada la guerra, una posición favorable respecto a las acciones contra el patrimonio artístico emprendidas por los alemanes fue fruto de la publicación colectiva Kunstschutz im Kriege. Berichte über den Zustand der Kunstdenkmäler auf den verschiedenen Kriegsschauplätzen und über die deutschen und österreichischen Massnahmen zu ihrer Erhaltung, Rettung und Erforschung. Leipzig: Seemann Verlag, 1919, editada por Paul Clemen, historiador e inspector de los monumentos de Renania. En este mismo sentido, resulta también de interés la opinión sostenida por las publicaciones españolas, entre las que recogemos la impresión de Gaziel en La Vanguardia casi un año después del bombardeo, suavizando, en cierta medida, los daños causados a la catedral: «Sin embargo, el mismo Señor que permitió tanta tribulación en su Casa, debió apiadarse de ella y preservarla de un aniquilamiento que parecía total y seguro. Es verdaderamente curioso observar que los desperfectos sufridos por la Catedral no están en proporción del grande aparato que ofreció el siniestro. [...] transcribiré únicamente las palabras de la Comisión oficial, encargada por el Gobierno de Francia de dictaminar sobre los daños causados á NotreDame: "En resumen" — dice el dictamen de la Comisión—: "Aunque desfigurada en sus líneas y en los detalles de su decoración, la Catedral de Reims subsiste. La construcción robusta ha resistido al choque de los proyectiles. Será posible restituir al edificio su techumbre y reparar su mampostería; pero no se le devolverán jamás sus esculturas, y la Catedral ostentará noblemente las huellas de un vandalismo que traspasa los límites de la imaginación”», GAZIEL, "Cartas a La Vanguardia desde Francia. En la región de Reims, VII, La Catedral (Conclusión)», La Vanguardia, 22 de agosto de 1915.

10. AleXAndre, A., Les monuments français détruits..., pág. 55.

11. Los daños en el interior de la iglesia fueron especialmente funestos. Los obuses incendiarios habrían prendido rápidamente al encontrar en la nave camas de paja que durante la ocupación alemana sirvieron para que sus tropas tuvieran 


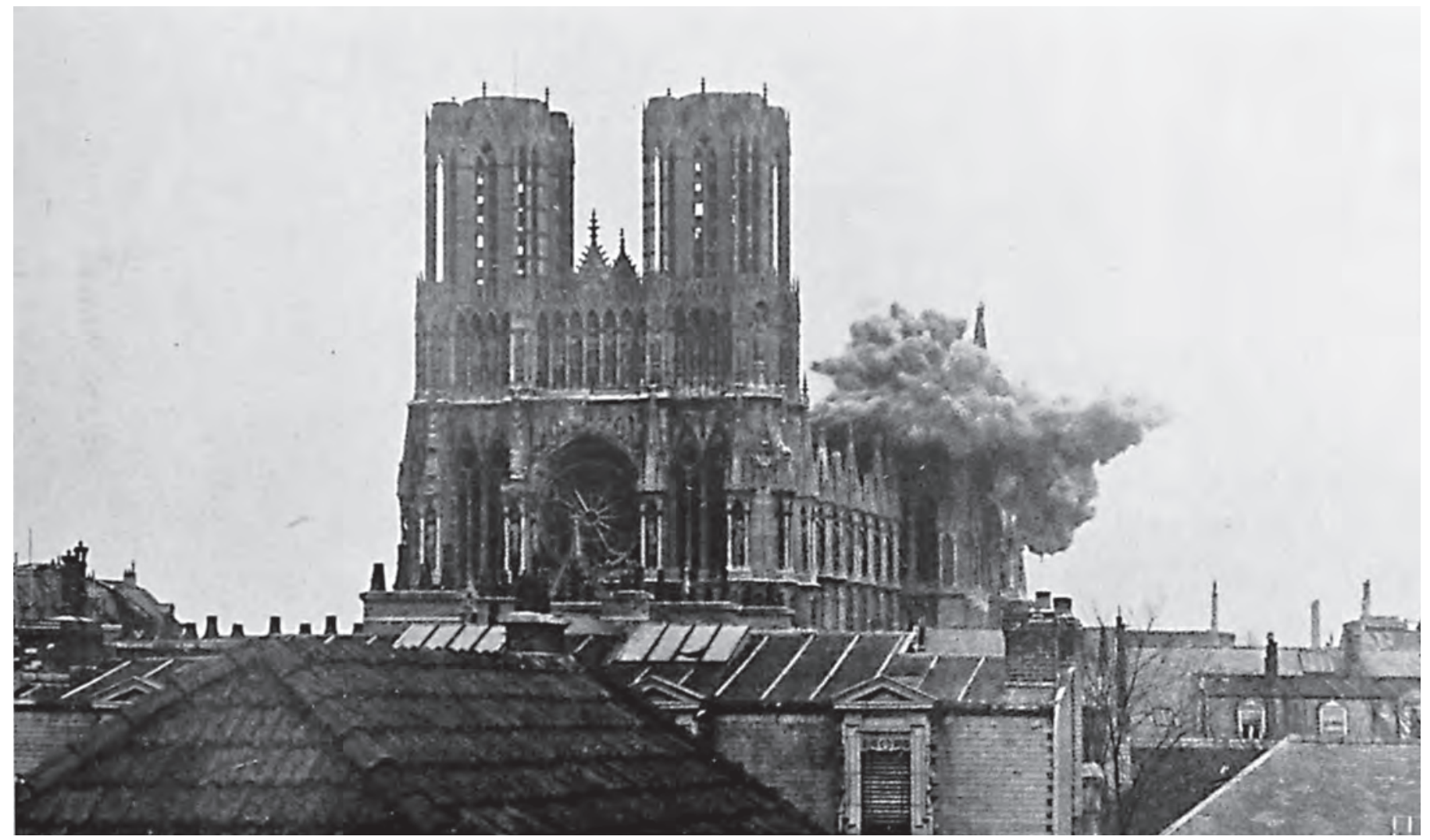

sastre. Pocos meses después de la fatídica fecha se produjeron nuevas pérdidas: el 19 de febrero de 1915 volvía a ser bombardeada la ciudad y en los sucesivos meses, la catedral (ilustraciones 4 y 5$).^{12}$

\section{PROPAGANDA E IDENTIDAD NACIONAL}

Muchos espacios religiosos de Francia sufrieron acciones similares a las de la catedral de Reims: las catedrales de Senlis, Verdún o Arras fueron igualmente bombardeadas por las tropas alemanas entre la primavera de 1914 y el verano de 1915. Pero la extraordinaria densidad simbólica que le concedía a Reims haber sido espacio de coronación de reyes y símbolo, por ello, de la nación y de su poder, fue decisiva para convertirla en mártir de guerra. ${ }^{13}$ Mutilada por el ejérci-
3. El bombardeo de la catedral de Reims.

Collier's New Photographic history of the world's war: including sketches, drawings and paintings made by artists at the front. Nueva York: P.F. Collier and Son, 1919, pág. 86 .

cobijo. Asimismo, el año anterior se había alzado un andamio sobre la torre norte para llevar a cabo trabajos de restauración, así que su estructura de madera contribuyó a avivar el daño. Véase PASSINI, M., «Martirio e resurrezione di Reims», en CASTelnuovo, E.; Sergi, G., Il Medioevo al passato e al presente. Arti e storia nel Medioevo. Turín: Einaudi, 2004, vol. Iv, pág. 572. La autora, que actualmente forma parte del Institut d'histoire moderne et contemporaine del Centre national de la recherche scientifique de París, es especialista en historia de los museos y patrimonio, así como en los procesos transnacionales entre política y arte, por consiguiente, aparece citada como autora de notables estudios de referencia que han sido útiles para el presente trabajo.

12. AleXandre, A., Les monuments français détruits..., pág. 65.

13. «Que le bombardement de Notre-Dame de Reims ait fait partie d'un plan déterminé, c'est une chose incontestable. Un otage, le plus grand de tous, voilà comment l'État-Major allemand considère la haute cathédrale royale. [...] Sur la pure noblesse de la cathédrale ils sont d'ailleurs parfaitement bien instruits. Ils savent qu'avec ses splendides tapisseries, ses riches verrières, 
4. Arsène

Alexandre

Les monuments

français détruits

par l'Allemagne:

enquête

entreprise

par ordre

de M. Albert

Dalimier,

sous-secrétaire

des Beaux-Arts.

París: Berger-

Levrault, 1918 ,

lám. 3.
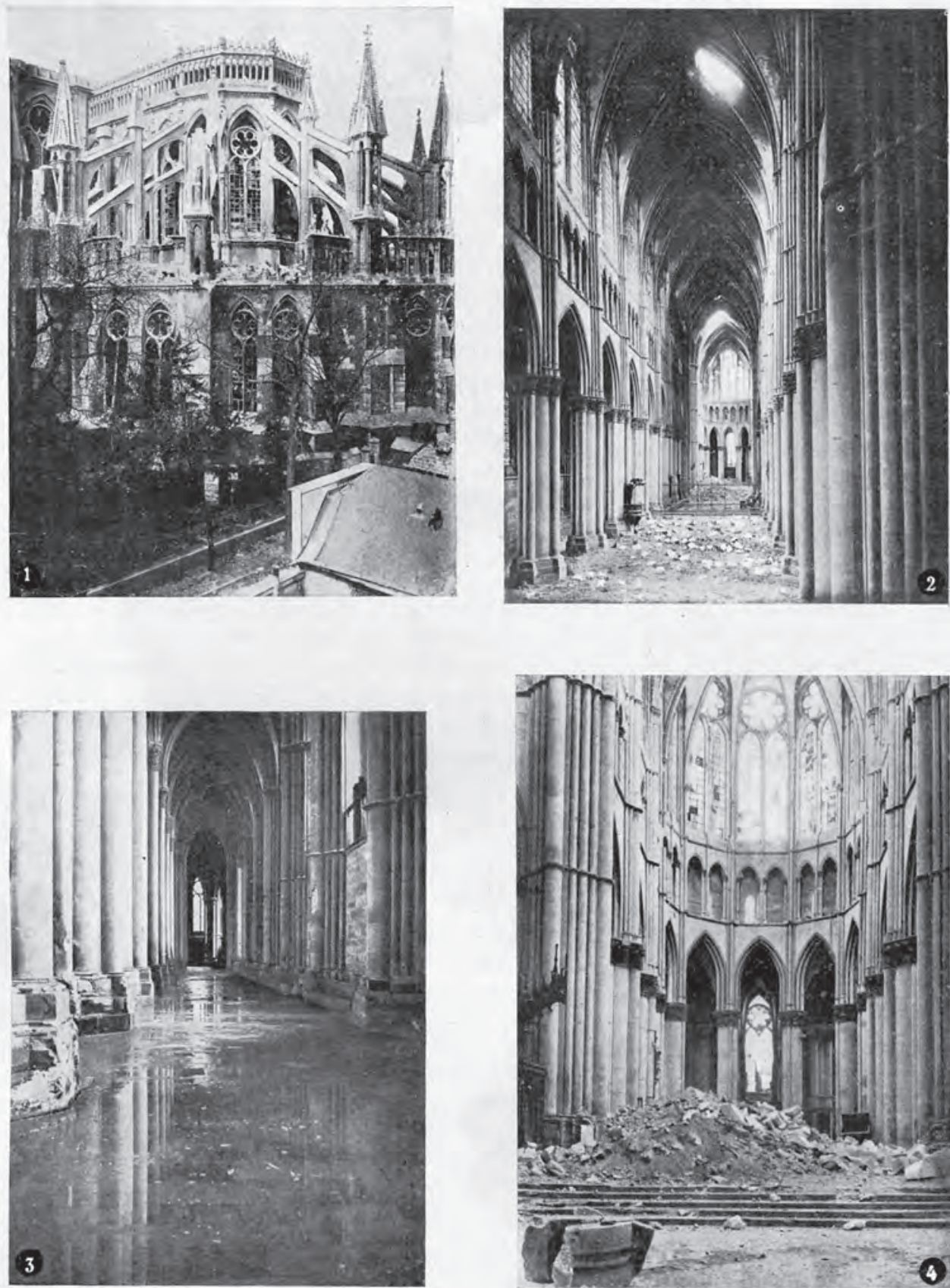

CATHÉDRALE DE REIMS

I. Vue générale de l'abside - 2, Bas coté nord.

3. Bas cóté sud. Les voútes ne reliennenl plus la pluie, juillet I9I6. - 4. Chaur.
Les $n$ os $\mathrm{I}, 2$ et 4 montrent les ravages opérés en avril 1917 . On remarquera dans le $n^{\circ} 4$ la destruction au mailre-aulel enseveli sous les décombres de la voúte.

( $\operatorname{Nos}_{1}, 2,3$, clicbés de M. Parchitecte Max Sainsaulieu; $n^{\circ}$ 4, cliché Section photographique de l'Armée.) 


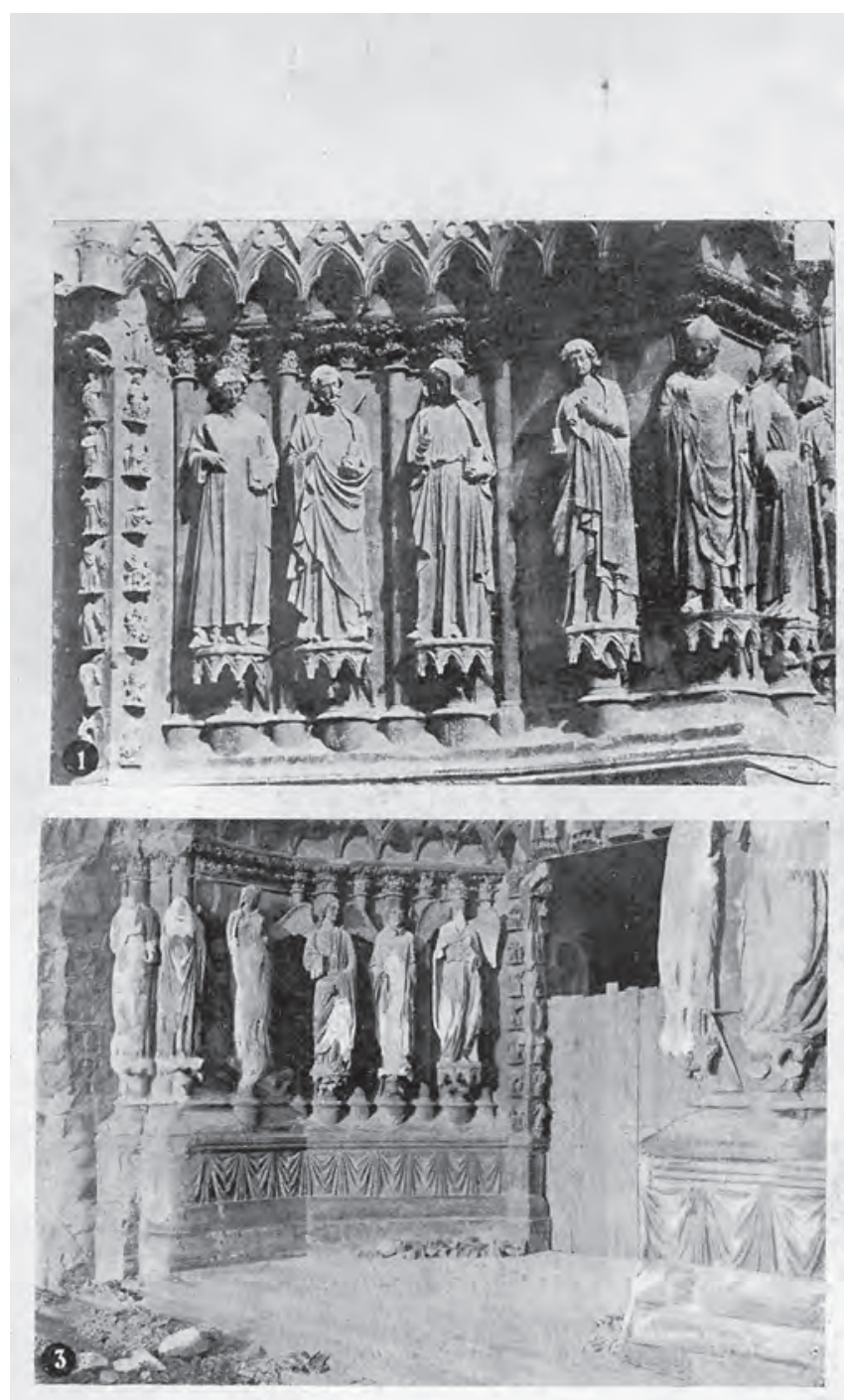

5. Arsène

Alexandre

Les monuments

PL. 5

français détruits

par l'Allemagne:

enquête

entreprise

par ordre

de M. Albert

Dalimier,

sous-secrétaire

des Beaux-Arts.

París: Berger-

Levrault, 1918,

lám. 5 .
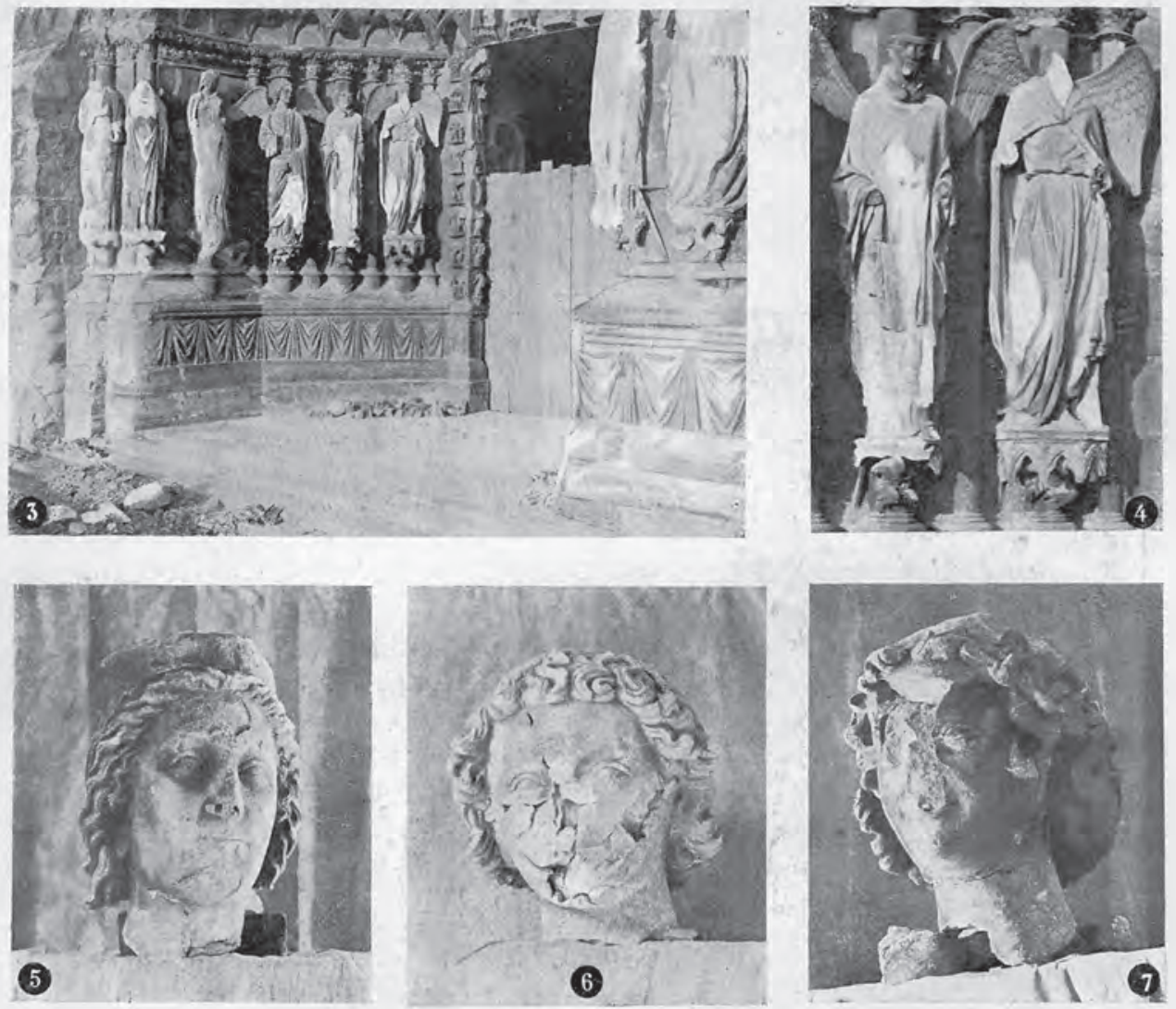

CATHÉDRALE DE REIMS

I. Sculptures de l'ébrasement d'un des portails de la façade avant la guerre.

3. Sculptures de l'ébrasement d'un àes portails de la façade, après le 19 septembre 1914.

2 et 4 . Délail du méme portail montrant la mutilation des statues par le feu.

5. Téle de la reine de Saba. -6 et 7 . L'ange dit le "Sourire de Reims », après réassemblage des fragments.

(Cliches Monuments bistoriques.) 
to alemán, Notre-Dame de Reims quedó canonizada en el subconsciente y el consciente colectivo de la nación.

Una ofensiva de ese calibre patrimonial, sentimental, ideológico y político, ${ }^{14}$ generó un notable movimiento de salvaguarda y exaltación de los bienes franceses manifestado en todo tipo de publicaciones. Aunque las empresas editoriales centraron su interés en Reims, no dejaron de lado el resto de ciudades y regiones devastadas o monumentos bombardeados. De esta manera, a los registros literarios y gráficos que acumulaban pérdidas patrimoniales, se sumaron las reflexiones de carácter teórico, perspicaces exponentes de un sentimentalismo de carácter nacional que transformaba la situación bélica poniendo los horrores de la guerra al servicio del pueblo francés. ${ }^{15}$

Tal circunstancia provocó que la ruina no se viera únicamente como una consecuencia del paso de los años, sino que se contemplara en ella la responsabilidad del presente ${ }^{16}$ y convirtió las obras patrimoniales en un instrumento de propaganda que propició un pacto de compromiso entre la política y la historia del arte. ${ }^{17}$ Así, se construyó un nuevo discurso nacional ante el van-

son Trésor, ses sculptures, elle constitue un musée d'art gothique sans analogue dans le monde. Une Bible de Pierre, d'une richesse incomparable, où sont inscrites l'Histoire des rois de France, la Légende de la création, la gloire des Saints Prophètes et des Apôtres», Les Allemands destructeurs de cathédrales..., pág. 9.

14. "Ainsi par-dessus le front, France et Allemagne se lançaient non seulement des obus, mais des arguments pour prouver chacune à l'autre sa supériorité dans le domaine de la culture. Tels jadis les héros d'Homère s'invectivaient au-dessus des remparts d'Ilion», BAzIN, G., «La bataille du gothique», Histoire de l'histoire de l'art de Vasari à nos jours. París: Albin Michel, 1986, pág. 271.

15. Sobre el bombardeo de la catedral de Reims véase n. 8, y en cuanto a la repercusión editorial de este acontecimiento se puede consultar Michel, A., "Ce qu'ils ont détruit», Gazette des Beaux-Arts, XII, 1914-1916, págs. 177-212, donde un inventario de los monumentos dañados se acompaña de una gran cantidad de ilustraciones. También la revista Les Arts, XIII, 154, abril 1916, cuyo número está consagrado a los monumentos destruidos. Asimismo, es especialmente notable el relato continuo que exponen los veinte números publicados por Armand Dayot en L'Art et les Artistes a lo largo del conflicto y que dedicó, monográficamente, a monumentos dañados, regiones bombardeadas o al arte de un país aliado. Véase DAYOT, A. (dir.), L'Art et les Artistes [a partir del año 1914 conocida como L'Art et les Artistes. Revue d'art ancien et moderne des deux mondes y dirigida por Madeleine Dayot desde 1934], publicada en París desde 1905 hasta 1936. El número fundamental de esta sección fue el dirigido por Camille Mauclair (MAUClaIR, C., «L'Art assassiné», L'Art et les Artistes, XIV, 157, 1917-1918). Sobre Armand Dayot y su actividad editorial, véase AguilAR, A.-S., «Armand Dayot», en SENECHAL, P.; BARBILlON, C. (dirs.), Dictionnaire critique des historiens de l'art actifs en France de la Révolution à la Première Guerre mondiale. París: Institut national d'histoire de l'art, 2009, disponible en http://www.inha.fr/fr/ressources/publications/publications-numeriques/ dictionnaire-critique-des-historiens-de-l-art/dayot-armand.html [fecha de consulta: 17 de enero de 2017]. En esta misma línea de revisiones locales se encuentran las propuestas editoriales: Images historiques, publicada entre 1915 y 1916 y con aportaciones de notables historiadores como Camille Enlart. Véase Images historiques: le mémorial des cités ravagées. París: Henri Laurens, 1915-1916. También la serie Villes meurtries de France, editada entre París y Bruselas por Van Oest. Véase Villes meurtries de France. París-Bruselas: G. Van Oest, 1920; así como la dirigida por Gabriel Louis Jaray [JARAY, G.-L. (ed.), La France dévastée, Série I, Les régions. París: Félix Alcan, 1919; idem, La France dévastée. Série II, Les faits. París: Félix Alcan, 1919-1921]. Por último, las publicaciones posteriores que revisan la catedral como icono simbólico de la historia francesa son, entre otras, la del artista e historiador del arte Étienne Moreau-Nélaton, quien publicó poco después del ataque $L a$ Cathédrale de Reims. París: Librairie centrale des beaux-arts, 1915; o la del medievalista Lucien Magne (MAGNE, L., La Guerre et les monuments. Cathédrale de Reims, Ypres, Louvain, Arras. París-Nancy: Berger-Levrault, 1915). También el historiador Louis Bréhier dedicó una obra a Reims (BréHIER, L., La Cathédrale de Reims. Une œuvre française. París: H. Laurens, 1916). Un poco posterior es la aportación de MARguillier, A., La Destruction des monuments sur le front occidental. Réponse aux plaidoyers allemands. París-Bruselas: G. Van Oest, 1919. Véase también Kunst, H.-J.; SchenkLUHN, W., Die Kathedrale in Reims: Architektur als Schauplatz politischer Bedeutungen. Frankfurt: Fischer Taschenbuch Verlag, 1988; LIOT, D. (dir.), Mythes et réalités de la cathédrale de Reims de 1825 à 1975, cat. exp., verano-otoño de 2001, Musée Saint-Rémi, Bibliothèque municipale, Musée du Fort de la Pompelle y Musée des Beaux Arts, Reims. París-Reims: Somogy - Ville de Reims, 2001; HaRLAUT, Y., La cathédrale de Reims: du 4 septembre 1914 au 1o juillet 1938: idéologies, controverses et pragmatisme, tesis doctoral. Département d'Histoire, Université de Reims Champagne-Ardenne, 2006; PAssınI, M., «Désastres modernes: témoignages et représentations», en: Preti, M.; SetTis, S., Villes en ruine. Images, mémoires, métamorphoses. París: Musée du Louvre - Éditions Hazan, 2015, pág. 278.

16. Makarius, M., Ruines. Représentations dans l'art de la Renaissance à nos jours. París: Flammarion, 2011 [2004], págs. 206-207.

17. Una aportación del papel de los historiadores del arte franceses en la construcción de la identidad nacional en PASsINI, M., «Histoire et historiens de l'art dans la Grande Guerre», en: La Fabrique de l'art national. Le nationalisme et les origines de l'histoire de l'art en France et en Allemagne, 1870-1933. París: Maison des sciences de l'homme et Centre allemand d'histoire de l'art, 2012, págs. 190-228. 

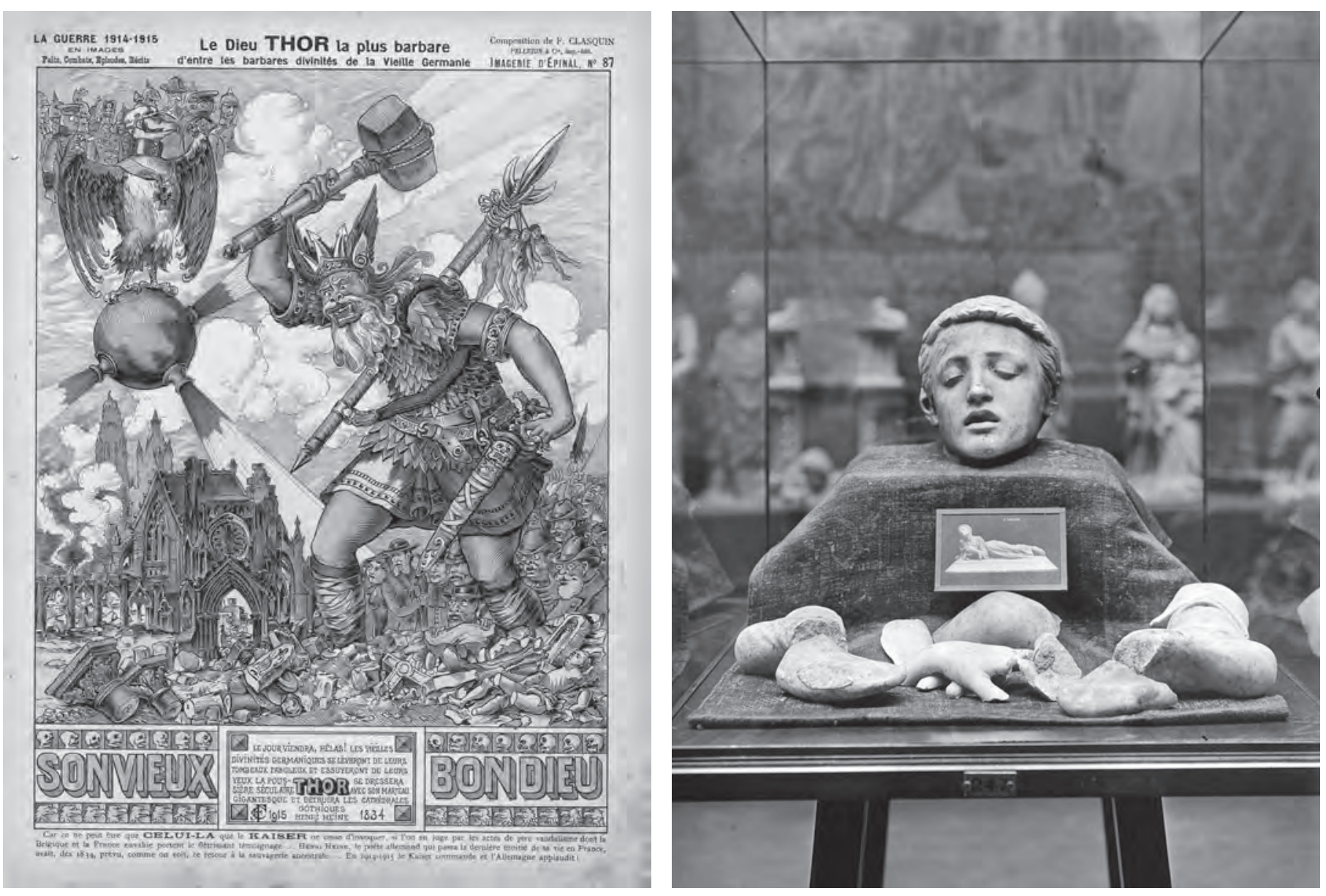

6. François Clasquin

(ilustrador) Le Dieu Thor, la plus barbare d'entre les plus barbares

divinités de la

Vieille Germanie, Imagerie

d'Épinal,

núm. 87 ,

La guerre 19141915 en images: faits, combats, épisodes, récits. Épinal: Pellerin et Cie., 1915. dalismo alemán, ${ }^{18}$ capaz de conmover a la población francesa a través de sus principales iconos artísticos, que no solo se expresó a través de publicaciones (ilustración 6), sino también gracias a un gran número de exposiciones dedicadas al patrimonio destruido. Entre estas, fue especialmente significativa la Exposition d'ouvres d'art mutilées ou provenant des régions dévastées par l'ennemi ${ }^{19}$ celebrada en el otoño de 1916 en el Petit Palais de París y cuyo título da una idea precisa del propósito al que sirvieron las casi doscientas obras expuestas (ilustración 7).

18. «On comprendra que ce n'est pas pour le plaisir de nous livrer à une simple dissertation philosophique que nous avons du principe qui, proclamé en Allemagne de l'école jusqu'au trône, détermina la guerre allemande, tiré tout ce qu'il renferme. Il s'agissait pour nous de préciser l'état de la question, au contraire dépouillée de toutes les obscurités dont les écrivains de l'ennemi ont voulu l'entourer après coup, et de toutes les dénégations par lesquelles ils ont essayé de la déplacer. Cette question est, tout entière, et uniquement, dans les trois propositions suivantes: quantité de monuments français ont été détruits, représentant une valeur d'art et d'histoire incalculable; ces monuments ont été détruits par l'Allemagne parce qu'elle se considérait comme en possession du maximum de force; cette force a été proclamée par les représentants officiels de la pensée allemande, marchant à la tête des armées allemandes avant la guerre, et à leur suite la guerre déchaînée, comme supérieure à tous les droits», ALEXANDrE, A., Les monuments français détruits..., págs. 5-6.

19. FAlCOU, R.; LAPAUZe, H.; FAUChIER-MAgnan, A. (comis.), Exposition d'ouvres d'art mutilées ou provenant des régions dévastées par l'ennemi. Organisée sous le patronage du sous-secrétaire d'État des Beaux-Arts par la Ville de Paris, sur l'initiative $d u$ «Journal», cat. exp., 15 de septiembre - 30 de octubre de 1916, Petit Palais, París. París: D. Niestlé, 1916. En cuanto al resto de las exposiciones, listamos las siguientes por orden cronológico: L'Art à la guerre, cat. exp., 20 de octubre - 30 de noviembre de 1915, Jeu de Paume des Tuileries, París. París: Jeu de Paume des Tuileries, 1915; Exposition des photographies de guerre prises sur les fronts de bataille par les sections photographiques des armées Anglaise, Belge, Française, Italienne, Russe, Serbe, cat. exp., 4 de octubre - 2 de noviembre de 1916, Pavillon de Marsan, Union Centrale des Arts Décoratifs, París. París: Union Centrale des Arts Décoratifs, 1916; La Guerre et les humoristes, exposition organisée par la Société des dessinateurs humoristes et la Société des artistes humoristes, cat. exp., abril-junio de 1917, Galerie La Boétie, París. París: La Boétie, 1917; Deuxième exposition interalliée de photographies de guerre, cat. exp., 15 de noviembre - 15 de diciembre de 1917, Salle du Jeu de Paume, París. París: [s.e.] 1917.
7. Alexandre Falguière San Tarsicio (fragmentos), 1868, mármol. Proveniente de la capilla del castillo de Gerbéviller, se mostró en la Exposition d'œuvres d'art mutilées ou provenant des régions dévastées par l'ennemi, Petit Palais, París, 1916. 


\section{LA DISPUTA DEL ARTE GÓTICO COMO TELÓN DE FONDO DE LA GUERRA}

El periodo de entreguerras, ${ }^{20}$ de especial dificultad para la diplomacia francoalemana, fue, sin embargo, fructífero para la labor de arqueólogos e historiadores. De hecho, su actividad se puede leer en paralelo a los acontecimientos históricos, no ya como consecuencia de ellos, sino como expresión de la mentalidad que los inspiraba. Al margen de los trabajos que denunciaron la destrucción del patrimonio, los que promovieron su recuperación y los que se publicaron con el afán de enaltecer la identidad nacional a partir de las obras o los monumentos afectados, Francia y Alemania desplegaron un intenso debate crítico sobre el arte y, en especial, sobre el origen del arte gótico. Su objetivo no era otro que utilizar ese origen como argumento decisivo en la construcción de su memoria histórica y, consecuentemente, de su hegemonía cultural e identidad nacional, argumento, sin embargo, que ya se había plasmado con anterioridad a ese periodo de entreguerras. ${ }^{21}$

20. Seguramente por tener la experiencia de Reims aún presente, los franceses se adelantaron al inicio de la Segunda Guerra Mundial y, poco antes de la declaración de guerra en septiembre de 1939, unos treinta y nueve convoyes de cinco a ocho camiones cada uno evacuaron las obras más representativas de los museos, obras cuya carga simbólica no era necesariamente identitaria en cuanto a la cuestión nacionalista sino como manifestación del poder cultural francés. Los lugares elegidos para la protección de las obras fueron castillos situados por lo general entre el sur de París y el margen norte del río Loira, el principal el de Chambord, y entre otros los de Aillières-Beauvoir, La Palice, Louvigny, Chèreperrine, Sourches y Courtalain, hasta llegar a una cincuentena. La compleja operación fue dirigida por Jacques Jaujard, que al año siguiente se convertiría en director de los Musées nationaux así como de la École du Louvre, y que durante la Guerra Civil española había colaborado en la evacuación de obras del Museo del Prado. Sobre esta circunstancia se puede consultar ARGERICH, I.; ArA, J. (eds.), Arte protegido. Protected art. Art protegé, cat. exp., marzo-abril de 2005, Palais des Nations, Ginebra. Madrid: Sociedad Estatal para la Acción Cultural Exterior - Museo Nacional del Prado - Instituto del Patrimonio Histórico Español, 2005. En cuanto a Jaujard, véase PALEwski, G., Notice sur la vie et les travaux de Jacques Jaujard (1895-1967) lue à l'occasion de son installation comme membre libre: séance du mercredi 20 novembre 1968. París: Institut de France, Académie des BeauxArts, 1968; Des Varennes, F., Jacques Jaujard: un bienfaiteur de la culture: Institut de France, Académie des Beaux-Arts, communication faite à la séance du 29 de février 1984. París: Institut de France, 1984. A pesar de las precauciones que se adoptaron, las obras evacuadas volvieron a peligrar cuando los alemanes, en junio de 1940, tomaron París. Se emprendió entonces otro desplazamiento hacia el sur, siguiendo el retroceso del gobierno y las tropas francesas. Si Reims había sido el objetivo simbólico a abatir y a su vez había servido para avivar el debate sobre el origen del gótico, nuevamente las obras de arte, en este caso obras muebles - pintura y escultura principalmente-, se verían subyugadas a propósitos de legitimación política. Véase VAlland, R., Le front de l'art. Défense des collections françaises 1939-1945. París: Réunion des Musées nationaux, 2014. Al respecto, hay que tener en cuenta que los nazis organizaron un informe que incluía largas listas de reclamaciones de piezas que, de una forma u otra, consideraban que podían relacionar con el contexto artístico germánico y que habían sido robadas al país, lo cual propiciaba que, al margen de reivindicar su victoria cultural, pretendiesen colmar con grandes obras la colección patrimonial del Tercer Reich. Esta tarea fue ordenada por el ministro de Propaganda Joseph Goebbels y recayó sobre el historiador del arte Otto Kümmel, que dio nombre al informe mencionado, Kümmel Report, consultable en línea en la web de la Thomas J. Watson Library del Metropolitan Museum of Art, disponible en http://library.metmuseum. org/record=b1231773 S1 (consultado: 17 de febrero de 2017). Véase KüMMEL, O., Bericht aufErlass des Herrn Reichsministers und Chefs der Reichskanzlei RK 118 II A vom 19. August 1940..., 3 vols. Alemania: Reichsministerium für Volksaufklärung und Propaganda, 1941. No hay que olvidar tampoco al respecto de esta situación de inestabilidad patrimonial la ley «relative à la déchéance de la nationalité à l'égard des Français qui ont quitté la France», promulgada en Vichy el 23 de julio de 1940 . Véase Journal officiel de la République française. Lois et décrets. 24 juillet 1940. París: Journaux officiels, núm. 180, 1940. El artículo primero dice: «Tout Français qui a quitté le territoire français métropolitain entre le 10 mai et le 3o juin 1940 pour se rendre à l'étranger, sans ordre de mission régulier émanant de l'autorité compétente ou sans motiflégitime, sera regardé comme ayant entendu se soustraire aux charges et aux devoirs qui incombent aux membres de la communauté nationale et, par suite, avoir renoncé à la nationalité française». El artículo segundo sigue así: «Les biens appartenant à ceux contre lesquels la déchéance de la nationalité française aura été prononcée par application de l'article précédent seront, à la requête du ministère public, placés sous séquestre par ordonnance du président du tribunal civil du lieu de leur situation».

21. La disputa sobre el origen francés o germánico del arte gótico precede a los acontecimientos del siglo xx y tuvo especial trascendencia en el siglo anterior, actuando como eslabón del proceso de construcción nacional de ambos países, que en aquel momento, con el romanticismo, daba sus primeros pasos. El debate también tuvo otros protagonistas como Inglaterra, que se sumó con aportaciones más eventuales. Estos últimos basaban su papel en la relación racial de su pueblo con la cultura normanda, aunque lo más probable es que tanto el gótico inglés como el francés descendieran de una misma raíz. Véase el problema inglés en RoMero BREST, J., «Courajod y el problema de los orígenes del arte gótico», en CouRAJOD, L., Los orígenes del arte gótico. Buenos Aires: Argos, 1946 [1890-1891, 1891-1892], pág. 32. Nuevamente, una síntesis del debate historiográfico entre Francia y Alemania se encuentra en PAssınI, M., «Le Gothique dans les historiographies de l’art françai- 


\section{LENTA FASCINACIÓN POR EL GÓTICO}

Históricamente, el interés por el arte gótico se ha manifestado de una manera desigual y resulta difícil entender la importancia de su recuperación en un contexto bélico si no se revisa su fortuna histórica. Hay que tener en cuenta al respecto que durante el Renacimiento se difundió la noción de un Medievo oscuro que interrumpía el progreso entre la Antigüedad y la Época Moderna.$^{22}$ Los siglos siguientes continuaron dando la espalda al arte medieval, y, una vez superado el misticismo propio del siglo XvII, el Neoclasicismo, expresándose desde el gusto promovido por las academias y la mentalidad racionalista, siguió ignorando, hasta apenas el último momento, los procesos artísticos medievales por mucho que estos tuvieran que ver con complejos procesos de abstracción - como en el caso del arte románico- o de elevación espiritual — como en el del gótico—. ${ }^{23}$ Pero fue quizá esta última característica la que funcionó como estímulo para algunas importantes personalidades de la segunda mitad del siglo XVIII cuando, especialmente en los campos de la estética y la literatura, empezaron a despuntar manifestaciones en favor del arte medieval que sirvieron de base, como se verá, al movimiento romántico.

Johann Wolfgang von Goethe llegó a Estrasburgo en abril de 1770 con veintiún años de edad. Impresionado por la singular belleza de su catedral, le dedicó una composición: el texto Von deutscher Baukunst, es decir, Sobre la arquitectura alemana. En sus líneas expresaba que el origen de la esencia gótica tenía nombre de arquitecto alemán, Erwin von Steinbach, maestro principal de obras de Estrasburgo. ${ }^{24}$ Con él, los partícipes del movimiento Sturm und Drang aceleraron la resurrección de la Edad Media, cuyo foco en Alemania fue Colonia. La catedral de la ciudad estaba inacabada desde $1560^{25}$ y fue en su culminación donde el espíritu romántico encontró el emblema de su movimiento. Johann Joseph von Görres, escritor y periodista alemán de tendencia nacionalcatólica, lanzó un llamamiento en favor de la conclusión del edificio el 20 de noviembre de 1814 y toda la nación se sintió implicada. ${ }^{26}$ Otros estímulos provenían, por ejemplo, de la obra del arquitecto Karl Friedrich Schinkel, quien había estudiado y difundido el saber sobre los monumentos góticos de Europa, y también de las obras de Caspar David Friedrich (ilustración 8), las cuales ejemplifican la traslación de este espíritu a la pintura. ${ }^{27}$

se et allemande. Stratégies de nationalisation et constructions croisées d'identités esthétiques», Regards croisés. Revue franco-allemande de recensions d'histoire de l'art et esthétique, 2, 2014, págs. 11-17.

22. Este sentimiento de inferioridad para con las artes de la Edad Media se transfirió de generación en generación a partir de las consideraciones de Giorgio Vasari; véase GatTo, L., Viaggio intorno al concetto di Medioevo. Profilo di storia della storiografia medievale. Roma: Bulzoni, 2002.

23. A este olvido medieval contribuyó especialmente el descubrimiento de las antiguas ciudades clásicas de Herculano, en 1738, y Pompeya, en 1748.

24. «Was braucht's dir Denkmal! Du hast dir das herrlichste errichtet; und kümmert die Ameisen, die drum krabbeln, dein Name nichts, hast du gleiches Schicksal mit dem Baumeister, der Berge auftürmte in die Wolken», GoETHE, J.W., Goethe Werke. Hamburgo: Hamburger Ausgabe, 1960, vol. xII, pág. 7.

25. Iniciada en 1248 a partir del coro - erigido entre esta fecha y 1322-, la catedral de Colonia se llevó a cabo intermitentemente hasta 1560, cuando las obras se interrumpieron. Convertida en símbolo nacional de la Alemania dividida por las guerras napoleónicas, su finalización se volvió una cuestión política y cultural apoyada por los intelectuales de la época. Véase Castelnuovo, E., «Il fantasma della cattedrale», en idem; SERGI, G., Il Medioevo al passato..., págs. 10-11.

26. VoN GöRRES, J.J., «Der Dom in Köln», Rheinischer Merkur, 151, 20 de noviembre de 1814. El paralelo entre esta cuestión y lo ocurrido con la catedral de Reims es evidente: ambos son ejemplo de un consenso nacional a favor de la reparación del patrimonio y la construcción, mediante este, de la historia cultural de su pueblo.

27. Un catálogo general sobre Karl Friedrich Schinkel es Snodin, M. (ed.), Karl Friedrich Schinkel: A Universal Man. New Haven - Londres: Yale University Press, 1991. En cuanto a Caspar David Friedrich, es especialmente significativa su glorificación simbólica de la arquitectura gótica con la obra El Soñador, 1835, óleo sobre tela, $27 \times 21 \mathrm{~cm}$. Museo del Hermitage, San Petersburgo. Sobre este artista se puede consultar el siguiente catálogo: Hofmann, W., Caspar David Friedrich. Pinturas y dibujos, cat. exp., 14 de octubre de 1992 - 6 de enero de 1993, Museo del Prado, Madrid. Madrid: Museo del Prado, 1992. 


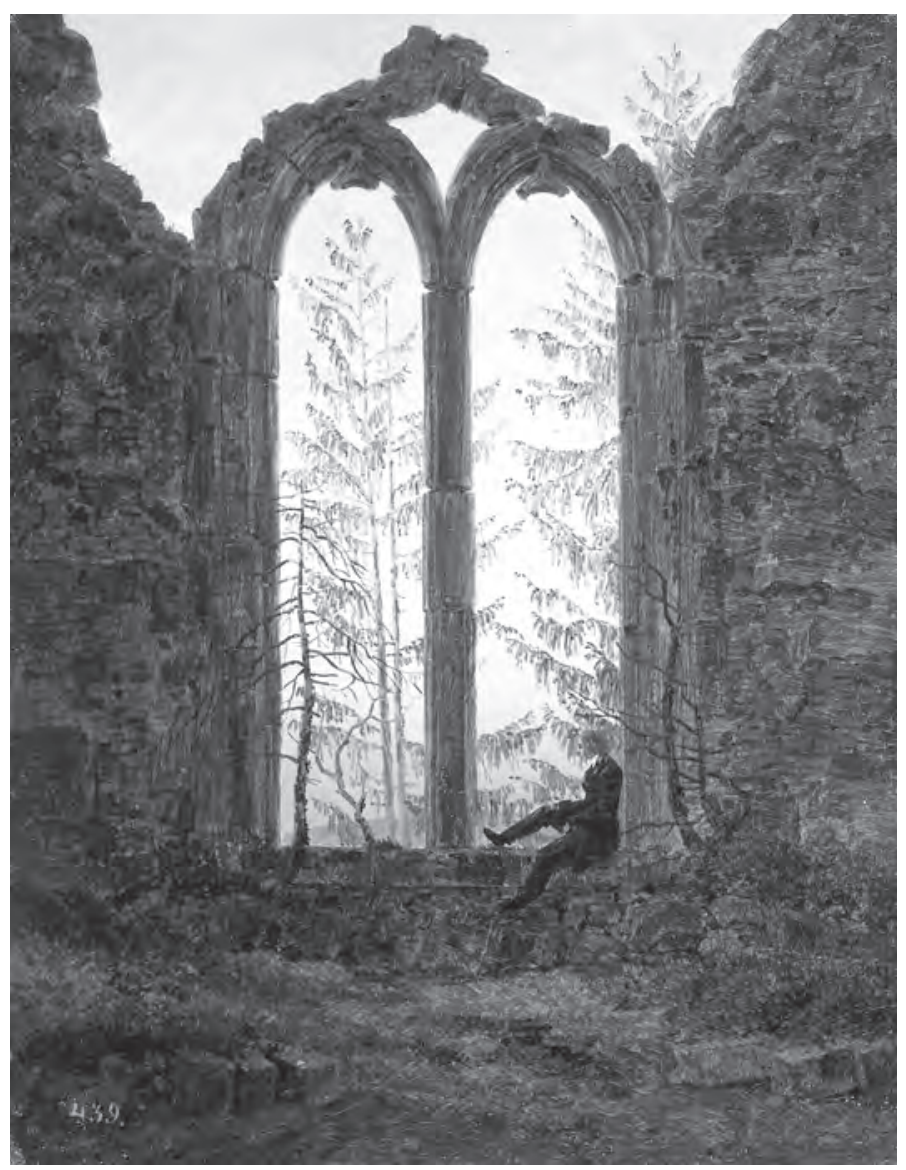

Igualmente relevante fue la aportación francesa al espíritu romántico y su consiguiente versión a la recuperación del gótico. De nuevo desde el ámbito de la literatura, escritores como François-René de Chateaubriand participaban en la construcción de la estética romántica a la vez que se hacían conscientes de la generalizada y metódica aparición de elementos góticos en la literatura. ${ }^{28}$ Pero lo gótico no se pudo volver mito sin antes pasar por Victor Hugo y su Notre-Dame de París ${ }^{29} \mathrm{o}$ Viollet-le-Duc y su reflexión teórica, que pocos años después llevaría a cabo ayudado por el también arquitecto Jean-Baptiste-Antoine Lassus. Ambos iniciaron la restauración de la catedral de París en $1843^{30}$ y tuvieron un papel definitivo en la construcción del imaginario gótico.

En el caso de Inglaterra, tercer componente en el debate - aunque mucho menos participativo en el aspecto identitario-, el pasado medieval había sido revisado ya con anterioridad. En respuesta al desmantelamiento de los espacios de culto promovido por el rey Enrique VIII entre 1536 y 1539, se habían sucedido sendos procesos de revisión y recu-

8. Caspar David Friedrich El soñador, 1835 , óleo sobre tela, $27 \times 21 \mathrm{~cm}$. Museo del Hermitage, San Petersburgo. peración de bienes. Por ejemplo, sir William Dugdale publicó en 1658 su historia de la catedral londinense ${ }^{31} \mathrm{y}$, en el siglo siguiente, la Society of Antiquaries of London editaba la revista $\mathrm{Ar}$ cheologia, con notables monografías sobre iglesias góticas inglesas así como investigaciones de

28. En un pasaje de Génie du Christianisme, publicada en París en 1802, Chateaubriand observa algunos elementos comunes de la nueva literatura romántica, luego retoma la antigua hipótesis según la cual la arquitectura gótica deriva de un modelo arbóreo: «Il est même curieux de remarquer que dans ce siècle incrédule, les poètes et les romanciers, par un retour naturel vers les mours de nos aïeux, se plaisent à introduire dans leurs fictions, des souterrains, des fantômes, un château, un temple gothique; tant ont de charmes les souvenirs qui se lient à la religion et à l'histoire de la patrie. [...] Les forêts des Gaules ont passé à leur tour dans les temples de nos pères, et ces fameux bois de chênes ont ainsi maintenu leur origine sacrée. Ces voûtes ciselées en feuillages, ces jambages qui appuient les murs, et finissent brusquement comme des troncs brisés, la fraîcheur des voûtes, les ténèbres du sanctuaire, les ailes obscures, les chapelles comme des grottes, les passages secrets, les portes abaissées; tout retrace les labyrinthes des bois dans l'église gothique; tout en fait sentir la religieuse horreur, les mystères et la divinité», Chateaubriand, F.-R. DE, «Des églises gothiques», en: idem, Génie du Christianisme. París: Migneret, 1802, t. III, I, VIII, págs. 23-24, 26-27. Castelnuovo considera (CASTElnuovo, E., «Il fantasma...», págs. 4-5), citando a E.H. Gombrich, que este origen arbóreo es una licencia que Chateaubriand habría tomado de William Warburton, obispo de Gloucester, durante su estancia en Inglaterra (Gomвrich, E.H., The Preference for the Primitive. Episodes in the History of Western Taste and Art. Londres: Phaidon, 2002, pág. 102).

29. Hugo, V., Notre-Dame de Paris, 1482. París: C. Gosselin, 1831. Publicada por primera vez en 1831 en dos tomos, ve su edición definitiva un año después.

30. Además de las transformaciones que el paso del tiempo produjo sobre la catedral, fue especialmente dañina la Revolución francesa. El proyecto de restauración se inició en 1843, pero los trabajos no empezaron hasta 1845 y se concluyeron en 1864, quedando al cargo Viollet-le-Duc después del fallecimiento de Lassus en 1857. Otras importantes aportaciones de Viollet-le-Duc a la canonización del arte gótico y, en especial, a la catedral, fueron su voz en el Dictionnaire raisonné o la Histoire d'un hôtel de ville et d'une cathédrale, publicaciones ambas donde defiende la función cívica de la catedral. VIOLLETLE-Duc, E.-E., Dictionnaire raisonné de l'architecture française du XI ${ }^{e}$ au XVI ${ }^{e}$ siècle, 10 vols. París: B. Bance (A. Morel), 18541868; idem, Histoire d'un hôtel de ville et d'une cathédrale. París: J. Hetzel, 1878.

31. Dugdale, W., The history of St. Pauls cathedral in London, from its Foundation untill these times: extracted out of originall charters, records, leiger books, and other manuscripts. Beautified with sundry prospects of the church, figures of tombes and monuments. Londres: Tho. Warren, 1658. 
carácter arqueológico e historiográfico. ${ }^{32}$ Un proceso que llegó a encumbrar el arquitecto Charles Locke Eastlake, principal autor de las teorías de la recuperación del gótico. ${ }^{33}$

Así, mitificando el arte gótico a través de su emblema formal, la catedral, ya fuese mediante la terminación - en Colonia - o la restauración - París—, ${ }^{34}$ se cerró el capítulo que recuperaba el arte medieval y se abría el de la lucha por su apropiación nacionalista y, posteriormente, el inicio de la diversificación disciplinar en la historia del arte. ${ }^{35}$

\section{LA DISCUSIÓN ACADÉMICA SOBRE EL ORIGEN DE UNA ARQUITECTURA MÍTICA}

A finales del siglo xIx, arquitectos, arqueólogos e historiadores ya habían trabajado con suficiente énfasis en la taxonomía y conocimiento de los monumentos góticos, aunque con alguna controversia tal como la expresa Alois Riegl, en 1903, en Der moderne Denkmalkultus: Sein Wesen und seine Entstehung:

Seit dem Aufkommen der Romantik, das heißt seitdem der Kultus des historischen Wertes überhaupt in eine letzte größte und entscheidendste Phase eingetreten ist, behaupteten in der kirchlichen Kunst die mittelalterlichen Stile und darunter insbesondere die uns aus zahllosen Denkmalen vertraute Gotik überwiegend den Vorrang. Der Grund dafür kann kaum zweifelhaftsein: in Wahrnehmung der Entfremdung, die zuletzt zwischen kirchlicher und profaner Kunst platzgegriffen hatte, lehnte sich die kirchliche Kunst vertrauensvoll an die Stile jener Zeiten an, in denen es zwischen kirchlicher und profaner Kunst noch keine Scheidung gegeben hatte. Diese Vorliebe für das Mittelalterliche und namentlich für das Gotische hatte eine Erscheinung im Gefolge, die man mit dem relativen Kunstwerte der profanen Denkmale wenigstens in Parallele setzen, wenn auch nicht schlankweg identifizieren kann. Noch heute werden die zuständigen Behörden fast täglich durch Projekte in Anspruch genommen, welche die Freilegung eines barock verbauten gotischen Portals, oder eines vermauerten Masswerkes, die Änderung eines barocken Zwiebeldaches in einen gotischen Helm, einer barocken Deckenmalerei in einen Sternenhimmel zum Gegenstände haben. Bei dieser Erscheinung ist gewiß die Renovierungssucht, die dem Neuheitswert Rechnung trägt, in sehr maßgebender Weise im Spiele;

32. Véase por ejemplo EFFEX, J., «Some Observations on Lincoln Cathedral», Archaeologia: or Miscellaneous tracts relating to antiquity, 4, 1786, págs. 149-159; «Observations on the Origin and Progress of Gothic Architecture, and on the Corporation of Free Masons supposed to be the Establishers of it as a regular Order. In a letter from Gov. Pownall, to the Rev. Dr. Lort, V. P.», Archaeologia: or Miscellaneous tracts relating to antiquity, 9, 1789, págs. 110-126; SAUNDERs, G., «Observations on the Origin of Gothic Architecture with an Appendix», Archaeologia: or Miscellaneous tracts relating to antiquity, 17, 1814, págs. 1-29.

33. EAstlake, C.L., A History of the Gothic Revival. Londres: Longmans, Green and co., 1872.

34. Al respecto se podrían recordar otros procesos de terminación de catedrales góticas, como el de la fachada de la catedral de Barcelona llevado a cabo con motivo de la Exposición Universal de 1888, bajo el patrocinio de Manuel Girona y el proyecto de Josep Oriol Mestres. Un año antes, Florencia inauguraba igualmente la fachada de Santa Maria del Fiore, llevada a cabo bajo proyecto de Emilio De Fabris.

35. Hemos prescindido de aproximaciones al tema en el resto de los ámbitos geográficos puesto que se desarrollan con procesos e intereses diferentes. Por ejemplo, en el caso de Italia, otro país con suficiente densidad histórica para verse apelado a tener voz en el debate, la recuperación del arte medieval giró en torno al arte lombardo y cómo su formación se debía diferenciar del «elemento bárbaro». «Fu così che il gran tema delle invasioni, delle origini della civiltà europea e dell'affermarsi delle moderne "nazioni" su cui in tutta Europa si affaticavano filosofi e storici, studiosi del diritto e della lingua, pittori e poeti, ruotò in Italia intorno alla "questione longobarda": una questione infida, sia per la scarsità e oscurità della documentazione, sia e soprattutto per le molte insidie connesse al tema della "fusione" o meno fra "due nazioni", una delle quali aveva, con Roma, dominato il mondo, e l'altra era stata a lungo considerata una popolazione "barbara fra le barbare"», BALBO, C., Della fusione delle schiatte in Italia. Lettere di Cesare Balbo agli estensori della Gazetta d'Augusta. Italia: [s.e.] 1844, pág. 48. Sobre este capítulo de la historia italiana, véase SolDANI, S., «Il Medioevo del Risorgimento nello specchio della nazione», en CASTElnuovo, E.; Sergi, G., Il Medioevo al passato..., págs. 149-186. 
es kann aber doch nicht zufällig sein, daß es in der Regel just gotische oder noch altere Werke sind, die man der hinzugekommenen Altersspuren entkleiden will. Daß kein vitales Kultusinteresse der Kirche dabei in Frage kommt, beweisen schon die zahlreichen Fälle, in denen seit Jahren einzelne Geistliche dagegen Stellung genommen haben; auch kann man in dieser Beziehung eine ähnliche Beobachtung machen, wie sie schon gelegentlich der Erörterung des Neuheitswertes zur Sprache gebracht worden war: daß die Tendenz auf Regotisierung der Denkmale hauptsächlich von der Landgeistlichkeit betrieben wird, während die Stadtgeistlichkeit sich dagegen zurückhaltender und in einzelnen Fällen sogar ablehnend verhält. ${ }^{36}$

En cualquier caso, la generación del cambio de siglo podía, ahora, desprenderse del espíritu romántico y dar paso a una aproximación al arte medieval basada en un saber empírico. Sin embargo, este nuevo saber, aun amparado en precisas técnicas científicas - como la arqueología - y contando con la incursión de la historia del arte en el mundo académico, ${ }^{37}$ no daba respuesta a todos los interrogantes, así que las especulaciones se dirigieron hacia los frentes aún abiertos, entre los cuales se encontraba quizá el más importante: esclarecer el lugar de nacimiento del arte gótico.

Un conato de discusión entre franceses y alemanes ya se había producido precozmente durante el primer tercio del siglo XIX. Cada una de las hipótesis — siempre de carácter apropiacionista - que se presentaba en un país, era desmontada por los argumentos del contrario. Así, a la consideración general de la procedencia francesa se oponían en 1824 el coleccionista e historiador de la arquitectura alemán Sulpiz Boisserée, ${ }^{38}$ en 1830 el arquitecto Johann Wetter mediante su guía sobre la catedral de Maguncia ${ }^{39}$ y el arquitecto germano Franz Mertens en $1843 .{ }^{40}$

Por parte francesa se podría citar, entre otros, al historiador, arqueólogo y estudioso de la «arquitectura bizantina» Félix de Verneilh, ${ }^{41}$ si bien es Louis Courajod, historiador y conservador del Musée du Louvre, quien puede considerarse ejemplo de la transformación del debate gótico. En él encontramos la última fase de la controversia incipiente del siglo xIX y el anticipo de la conversión de esta, con motivo del bombardeo de Reims y el enfrentamiento bélico francoalemán de la primera mitad del siglo xx, en una cuestión de primer orden en la lucha entre potencias contrarias. El interés de Courajod por el estudio de los orígenes del arte románico y gótico le había llevado a plantear, en diversas monografías, la hipótesis de que el pueblo franco

36. RIEGL, A., Der Moderne Denkmalkultus: Sein Wesen und seine Entstehung. Viena-Leipzig: W. Braumüller, 1903, págs. 63-64.

37. Es importante valorar el peso que pudo tener la institucionalización de la historia del arte como disciplina académica en las universidades de Europa y Norteamérica, un hecho que se produjo justo en este preciso momento, el cambio del siglo XIX al xx. Como resulta obvio, la nueva especialidad tenía un lugar privilegiado para el arte medieval, cuyo estudio precedía, como hemos visto, con mucho, a la incorporación de la materia en las facultades.

38. «Nous avons déjà indiqué, dans la première partie de nos rechercher, publiées avec les planches de la cathédrale de Cologne, les raisons qui nous font attribuer aux Allemands, si non l'invention, du moins le plus grand perfectionnement de cette admirable architecture; nous avons dit aussi par quels motifs on peut la nommer l'architecture germanique», BOISSERÉE, S., «Mémoire sur l'architecture du Moyen Âge», Revue Éncyclopédique, xxIv, 1824, págs. 583-584.

39. Wetter, J., Geschichte und Beschreibung des Domes zu Mainz. Maguncia: C.G. Kunze, 1835. Citado por FrankL, P., The Gothic. Literary Sources and Interpretations through Eight Centuries. Princeton: Princeton University Press, 1960, págs. 525-526.

40. Mertens, F., «Paris baugeschichtlich im Mittelalter», Allgemeine Bauzeitung, III, 1843, págs. 159-167 y 253-263, citado por PAssini, M., «Le Gothique dans...», pág. 12.

41. «En Allemagne, comme en France, ce combat de deux systèmes rivaux, qui ne se faisaient pas de concessions, ne saurait s'expliquer que leur l'origine étrangère et par la brusque introduction de l'un d'eux. Au XIII siècle, la France aurait été pour l'Allemagne ce que l'Italie fut pour toute l'Europe au XVI ${ }^{e}$. [...] C'est dans la France du Nord, dans la France française, dans ce noyau de la monarchie dont Paris est le centre géographique, et qui ne comprend ni la Flandre wallonne, ni la Lorraine et l'Alsace germaniques, ni la celtique et sauvage Bretagne, ni les provinces de la langue d'oc, que l'art ogival a été lentement enfanté; on y voit les innovations se produire, s'échanger rapidement, et enfin se convertir en un système. [...] Dans la seule France du Nord domine sans partage l'art ogival primitif. C'est de là qu'il s'est répandu dans toute l'Europe; c'est de ce foyer qu'il a rayonné dans toutes directions», VERNEILH, F. DE, «Origine française de l'architecture ogivale», Annales archéologiques, II, 1845, págs. 158-159. Sobre esta discusión véase PAssinI, M., «Félix de Verneilh», en: SÉNÉCHAL, P.; BARBILlon, C. (eds.), Dictionnaire critique des historiens de l'art actifs en France... 
-al cual se refiere como «el genio francés», dando muestra de su inmersión en el léxico romántico-fue el promotor del paso de la tradición galorromana y latina a la nueva visión medieval. ${ }^{42}$

Llegados a este punto, no parece erróneo pensar que en el área cultural francófona, la génesis gala del gótico estaba generalizada y aceptada en el ámbito académico. Así queda constatado por Émile Mâle, quien creía firmemente que los alemanes no podían sino encontrar el origen del gótico en las catedrales francesas, ${ }^{43}$ tesis que repitió continuamente en sus obras y, especialmente, en la que fue la versión pública de su tesis doctoral, L'Art religieux du XIII siècle en France, étude sur l'iconographie du Moyen-Âge et sur ses sources d'inspiration, publicada en $1898 .{ }^{44}$ Una obra de gran repercusión que se convirtió en el manifiesto de la politización del arte medieval en Francia.

Por su parte, la historia del arte alemana del siglo xx inauguraba las teorías acerca de la psicología del estilo. Su principal mentor, Wilhelm Worringer, también contribuyó al debate en una aportación que se podría tildar de carácter abiertamente abstracto, ya que no tenía como objeto de reflexión el arte sino el sujeto gótico. ${ }^{45}$ Worringer incurre en una justificación al centrar su hipótesis en la necesaria diferenciación entre dos conceptos, «gótico» y «goticismo». Lo «gótico» quedaba adscrito al campo formal —el sistema gótico-, mientras que el «goticismo» sería la condición, la disposición, la energía y el alma del pueblo, características cruciales para el desarrollo de la nueva expresión artística y antes mencionada como «sujeto gótico». El primer concepto era de procedencia extranjera - francesa-, la condición espiritual, en cambio, una exclusividad germánica. ${ }^{46}$ En suma, Worringer planteaba en los primeros años del siglo xx el

42. En cuanto a las monografías debidas a Louis Courajod, nos referimos a los cursos dictados en la École du Louvre entre los años 1890 y 1895: École du Louvre. Leçon de réouverture du cours de l'histoire de la sculpture du moyen âge et de la Renaissance. París: L. Cerf, 1890; École du Louvre (1890-1891). Les Origines de l'art gothique, leçon d'ouverture du cours d'histoire de la sculpture française. París: E. Leroux, 1892; École du Louvre (1891-1892). Les Origines de l'art gothique (les sources du style roman du VIII ${ }^{e}$ au XI ${ }^{e}$ siècle), leçon d'ouverture du cours d'histoire de la sculpture du moyen âge et de la Renaissance. París: L. Cerf, 1892; École du Louvre, 1892-1893. Les Origines de l'art gothique (premiers temps romans), leçon d'ouverture du cours d'histoire de la sculpture du moyen âge, de la Renaissance et des temps modernes. París: E. Leroux, 1892; École du Louvre. Cours d'histoire de la sculpture. Fragments de la leçon professée le 14 décembre 1892. París: E. Bouillin, 1893; École du Louvre, 1893-1894. Les Origines de l'art moderne, leçon d'ouverture du cours d'histoire de la sculpture du moyen âge, de la Renaissance et des temps modernes. París: E. Leroux, 1894; École du Louvre, 1894-1895. Cours d'histoire de la sculpture du moyen âge, de la Renaissance et des temps modernes. Leçon du 5 décembre 1894. Les Origines de l'art moderne. II. L'école académique. París: De D. Dumoulin, 1895. Es de especial interés la edición castellana, compuesta en base a los seminarios impartidos entre 1890 y 1892 y que recibe el título de Los orígenes del arte gótico. Véase n. 21.

43. "les Allemands étudient chez nous les origines de l'architecture ogivale qu'ils ne croient plus avoir inventé», MÂLE, É., «L'enseignement de l'histoire de l'art dans l'université», Revue Universitaire, 1, 1894, pág. 14.

44. "Au XIII 'siècle, riches et pauvres ont les mêmes joies artistiques. Il n'y a pas d'un côté le peuple et de l'autre une classe de prétendus connaisseurs. L'Église est la maison de tous, l'art traduit la pensée de tous. L'est pourquoi, si notre art du XVI ${ }^{e}$ ou du XVII ${ }^{e}$ siècle nous apprend peu de chose de la pensée profonde de la France de ce temps-là, notre art du XIII ${ }^{e}$ siècle, au contraire, exprime pleinement une civilisation, un âge de l'histoire. La cathédrale peut tenir lieu de tous les livres. Et ce n'est pas seulement le génie de la chrétienté, c'est le génie de la France qui éclate ici. Sans doute, les idées qui ont pris corps dans nos cathédrales ne nous appartiennent pas en propre: elles sont le patrimoine commun de l'Europe catholique. Mais la France se reconnaît à sa passion de l'universel. Seule, elle a su faire de la cathédrale une image du monde, un abrégé de l'histoire, un miroir de la vie morale. Ce qui appartient encore à la France, c'est l'ordre admirable quelle a imposé à celle multitude d'idées comme une loi supérieure. Les autres cathédrales du monde chrétien, qui toutes sont postérieures aux nôtres, n'ont pas su dire tant de choses, ni les dire dans un si bel ordre. Il n'y a rien en Italie, en Espagne, en Allemagne, en Angleterre qui puisse se comparer à Chartres. Nulle part on ne trouve une pareille richesse de pensée. Si l'on songe à tout ce que les guerres religieuses, le mauvais goût, et les révolutions ont détruit dans nos cathédrales, la riche Italie elle-même paraîtra pauvre. Quand donc voudrons-nous comprendre que dans le domaine de l'art, la France n'a jamais rien fait de plus grand?», MÂLE, É., L'Art religieux du XIII ${ }^{e}$ siècle en France, étude sur l'iconographie du Moyen-Âge et sur ses sources d'inspiration. París: E. Leroux, 1898, págs. 502-503.

45. La hipótesis del origen alemán del arte gótico se halla ya en un estudio precedente: WorRINGER, W., Abstraktion und Einfühlung. Ein Beitrag Zur Stilpsychologie. Neuwied: Heuser, 1907; traducido al español como Abstracción y naturaleza. México - Buenos Aires: Fondo de Cultura Económica, 1953. Sin embargo, es conveniente citar el volumen donde desarrolla esta idea al completo: Worringer, W., Formprobleme der Gotik. Múnich: Piper, 1911; que a su vez se tradujo al español como La esencia del estilo gótico. Buenos Aires: Nueva Visión, 1967.

46. «Los germanos no son, pues, los únicos que tienen arte gótico ni los únicos que lo crean; los celtas y los romanos poseen la misma importante participación que ellos en la evolución gótica. Pero los germanos son la "conditio sine qua non" del goticismo», Worringer, W., La esencia del estilo gótico..., págs. 39-40. Y más adelante prosigue (pág. 113): «Sin embargo, no puede decirse que sea Francia el propio hogar y patria del gótico. Lo que en Francia nació no fue el goticismo, sino el 
hermanamiento de una capacidad de expresión con una etnia concreta, lo que poco después se convertiría en base de las populistas especulaciones sobre la superioridad de la raza aria.

La respuesta francesa a este planteamiento surge en un momento entre la conmoción y el desgaste causados por la Primera Guerra Mundial en general y el daño causado en Reims en particular. Así, en 1917, el medievalista Camille Enlart escribía a Émile Mâle sobre la necesidad de intercambiar el término «gótico» por el de «francés» como maniobra para fusionar los dos conceptos e introducirlos como tal en el lenguaje colectivo artístico. ${ }^{47}$ Un año después, Mâle definía de nuevo el arte alemán como un arte que se alimentaba de referencias extranjeras, especialmente las francesas, en vez de desarrollar su capacidad de invención. ${ }^{48}$ Poco más tarde, ya finalizada la contienda, Henri Focillon escribiría al respecto que el arte gótico era, sin ningún tipo de discusión, francés, tanto en origen como en desarrollo. ${ }^{49}$ Igualmente, Marcel Aubert, en una obra consagrada a la memoria artística de las regiones devastadas por la guerra, definía el arte gótico como el orgullo nacional francés..$^{50}$

\section{¿Fue el fin de la Primera Guerra Mundial EL FIN DE LA DISPUTA?}

La disputa sobre el arte gótico, que no podemos seguir en este artículo, continuó en el periodo de entreguerras y se recrudeció con la Segunda Guerra Mundial. En este aspecto es extremadamente significativa la posición intelectual tomada por Pierre Francastel, que tras distanciarse de los hechos ocurridos en la Primera Guerra Mundial consideró que el periodo de entreguerras había sido un momento especialmente fructífero para el discurso alemán, intuyendo que las aportaciones de los arqueólogos e historiadores fueron necesariamente instrumentalizadas en beneficio de la solidificación del nacionalismo y de la política del Tercer Reich (ilustración 9).

Il me semble que la question de la propagande historique faite par l'Allemagne entre les deux guerres a une portée considérable en ce qui concerne la compréhension de ses méthodes et de ses buts, et qu'elle doit servir d'avertissement pour l'avenir. ${ }^{51}$

sistema gótico. [...] Y así sucede que aun los más bellos y maduros edificios góticos de Francia tienen un hálito innegable de sensibilidad orgánica y renacentista. Nunca llegan al total verticalismo; siempre tienen algunas compensaciones de horizontalidad. Así, pues, puede decirse que Francia ha creado los edificios góticos más bellos y más vivientes, pero no los más puros. El país del goticismo puro es el Norte germánico».

47. "Dans ma nouvelle édition je remplace dans une largue mesure le terme "gothique" par le mot "français". Je voudrais ramener cette expression primitive et légitime dans le langage courant, sans me flatter toutefois de supprimer l'autre. Le mot rentré dans l'usage, la notion entrerait plus nettement dans les idées reçues du grand public»: carta de Camille Enlart a Émile Mâle, fechada el 12 de mayo de 1917, citada por PAssinI, M., «Le Gothique dans...», pág. 11. Tal sustitución se haría efectiva en la nueva edición del texto: EnLART, C., Manuel d'archéologie française: depuis les temps mérovingiens jusqu'à la Renaissance. París: A. Picard, 1919-1932 [1902].

48. MÂLE, É., L'art allemand et l'art français du Moyen-Âge. París: Colin, 1917.

49. «Cette forme surprenante de l'art de bâtir, on l'appelle art gothique. C'est art français qu'il faut dire. Rien de plus français par les origines comme par le développement», Focillon, H., Les Pierres de France. París: H. Laurens, 1919, pág. 59.

50. «Ce beau pays est aussi le berceau de notre art national du Moyen-Âge, de notre architecture gothique, que l'on pourrait plus justement appeler française», AuBerT, M., Les Trésors d'art de la France meurtrie. París: Éditions de la Gazette des BeauxArts, 1921, pág. 5 .

51. Francastel, P., L'histoire de l'art instrument de la propagande germanique. París: Librairie de Médicis, 1945, pág. 7. Esta obra es la transcripción del curso homónimo dictado entre 1939 y 1940 en Clermont-Ferrand, residencia circunstancial de la Universidad de Estrasburgo tras la declaración de guerra de 1939. No fue hasta 1945, después de la capitulación alemana, cuando Francastel emprendió su publicación. En 1970, la editorial Mouton, con sede en la ciudad de París, reeditó el texto de forma idéntica bajo otro título sin hacer mayor referencia a tal cambio. Nos referimos a FrANCASTEL, P., Frontières du gothique. París: Mouton, 1970 [1945] (ilustraciones 10 y 11). Un extracto del texto original es estudiado en ARNoux, M.; 
Aunque el autor no aporta casos concretos, su hipótesis se basa en que la politización de la historia del arte se habría dado a partir de su relación con otras disciplinas sociales - historia, arqueología, economía - en el contexto de la universidad.

Il est important de souligner les fondements «universitaires» de certains aspects de la doctrine nazie; non que son fondateur ait suivi les cours des Universités, mais parce que, justement, on a tendance à ignorer les liens qui existent entre les spéculations, soi-disant désintéressées, de la science allemande, et les revendications d'un tribun démagogue..$^{2}$

Una vez filtrado algo del contenido cultural a las disciplinas más técnicas, estas, estrechamente ligadas a teorías políticas, habrían facilitado su instrumentalización en casos como el de la disputa del gótico. Y es que, pese a que la historia del arte siempre había dispuesto de información valiosa para la reconstrucción de la historia social, no empezó a consolidarse hasta que recibió el apoyo de disciplinas históricas abandonando su lugar de reclusión y privilegio simbólico.

Il me semble, d'autre part, que la portée des problèmes que se pose l'histoire de l'art, dès qu'elle renonce à n'être, comme trop souvent, qu'une classification abstraite, est généralement méconnue en France par la majorité des cercles universitaires. À côté de la pure archéologie, on n'y connaît guère qu'une histoire de l'art mondaine à base de snobisme. Toute occasion doit être bonne pour souligner la portée scientifique de ce mode d'enquête et d'interprétation par la connaissance non seulement du cadre extérieur de la vie passée, mais encore des formes les plus complexes de la culture d'une époque. L'histoire de l'art commence seulement à prendre sa place, chez nous, parmi les disciplines historiques. Mais elle n'est pas moins de l'histoire que la science des institutions ou l'économie ou la politique pure. Son plus grand tort a été de s'isoler, un peu orgueilleusement. $^{53}$

ÉDITIONS POLITIQUES, ÉCONOMIQUES ET SOCIALES LIBRAIRIE DE MÉDICIS - PARIS

Gaehtgens, T.-W.; Kitschen, F., Perspectives croisées: la critique d'art franco-allemande; 1870-1945. París: Éditions de la maison des sciences de l'homme, 2009, publicación que pretende reconstruir, mediante una selección de diferentes relatos y documentos históricos, las vicisitudes partidistas y las instrumentalizaciones políticas del arte entre Francia y Alemania.

52. Francastel, P., L'histoire de l'art instrument..., pág. 7. Es interesante recordar al respecto que el ámbito académico universitario como espacio de confluencia de pensamiento y de posible persuasión partidista entre las dos potencias, Francia y Alemania, ha sido analizado con brillantez por Michel Espagne y Michael Werner. Los autores trazan una historia de la transferencia cultural que tiene, entre sus espacios y momentos más significativos, la ciudad de Estrasburgo como puerta de entrada del pensamiento alemán en Francia desde el siglo XvIII, la creación de la École pratique des hautes études en 1866, supliendo los vacíos metodológicos con el modelo de la escuela alemanas, o el traslado de profesores alemanes a universidades francesas; véase EsPAGNE, M.; WERNER, M., «La construction d'une référence culturelle allemande en France: genèse et histoire (1750-1914)», Annales. Économies, Sociétés, Civilisations, 4, 1987, págs. 969-992.

53. FrancAstel, P., L'histoire de l'art instrument..., págs. 7-8. Una estrecha relación de causa-consecuencia entre politización del pensamiento y conflicto bélico es apuntada por Mathilde Arnoux (ARNOux, M., «Pierre Francastel: Commen-

9. Pierre Francastel L'histoire de l'art instrument de la propagande germanique. París: Librairie de Médicis, 1945 portada. 
On heurtera sans doute, sur ces points, deux groupes de lecteurs. En France même, beaucoup railleront - du moins parmi les érudits - les prétentions d'un historien de l'art. C'est une tendance très répandue que de considérer cette discipline comme une chose de luxe, sans grande valeur méthodique ni pratique. On a pris chez nous l'habitude d'opposer, parmi les enseignements universitaires, ceux qui sont fondés sur une science - la philologie, l'histoire, la géographie - et ceux qui sont fondés sur des connaissances dites subjectives : I'histoire de l'art, celle de la musique, voire celle de la littérature. C'est une attitude peu scientifique, cependant, que de prétendre introduire une discrimination de principe entre les faits suivant leur origine ou leur nature. L'apparition des cathédrales ou la transformation de Florence au quattrocento constituent un ordre de faits aussi précis et aussi significatifs que l'organisation administrative et judiciaire de la France monarchique ou que les courants économiques du monde contemporain.

Je ne pense pas que personne puisse sérieusement soutenir que l'histoire des institutions ou l'histoire économique apportent des certitudes définitives et qu'elles échappent à la loi générale qui pèse sur toute science : l'impossibilité de rassembler la totalité des faits. Les philologues n'ont sans doute pas la naiveté de penser qu'ils détiennent des vérités premières - en vertu de quelque privilège extra-scientifique. Toute science est conjecture parce qu'elle détermine arbitrairement et la matière de son enquête - la notion même de fait - et sa méthode d'interprétation. La science consiste justement dans la définition forcément limitée des points de vue et dans l'objectivité des interprétations.

Les Allemands ne manqueront pas de dire, de leur côté que les points de vue d'un Français sont aussi suspects de parti pris et de chauvinisme que les leurs. Je n'ignore pas la difficulté. Je ne suis pas assez naïf pour croire que les Frangais disposent, à l'exclusion de toute autre nation, de la

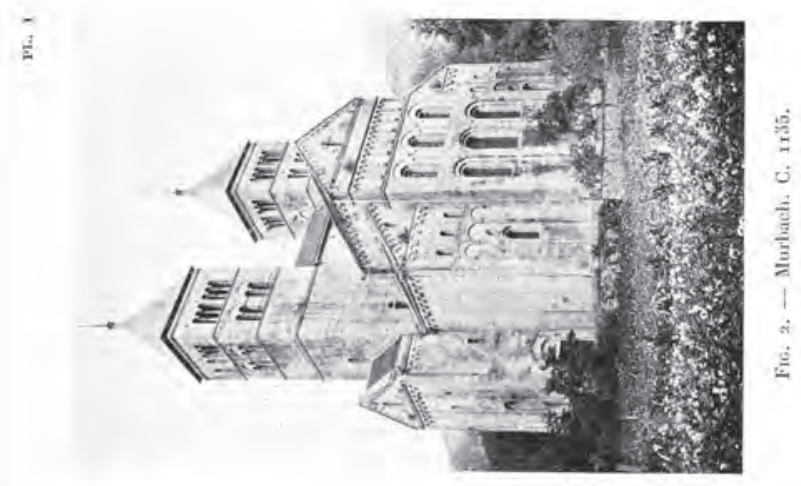

10. Pierre

Francastel

L'histoire de l'art

instrument

de la propagande

germanique.

París: Librairie

de Médicis, 1945,

pág. 16 y lám. 1.
Finalmente concluye:

Ou reste, l'art gothique ne doit pas être considéré comme la création d'un groupe national quelconque; il est le fruit d'une nouvelle conscience internationale en voie de développement. L'art gothique n'est pas, comme le roman, le résultat d'une évolution formelle; il est l'art des temps nouveaux, l'art de l'avenir. Si, après cela, il faut bien constater que c'est sur le territoire français qu'il a d'abord produit quelques-unes de ses plus belles œuvres, c'est tout simplement parce que c'est en France que le mélange —d'où est sortie l'Europe médiévale-des anciennes races et des nouvelles avait été le plus complet. L'art gothique ne saurait être identifié avec l'art des Barbares, mais c'est le sang barbare qui a renouvelé et fécondé le vieux sol en voie d'épuisement. ${ }^{54}$

Se puede considerar que a partir de esta aportación de Francastel, el debate dejó de centrarse en la cuestión del origen y empezó a desarrollarse en el campo del análisis historiográfi-

taire», en: ARnoux, M.; GAeHtgens, T.-W.; KITSChen, F., Perspectives croisées..., pág. 512). La autora se refiere a la posibilidad de que la educación intelectual alemana hubiese tenido cierta responsabilidad en la victoria de Prusia en la guerra francoprusiana. Conflicto que puede verse como el inicio de la tensión política de época moderna entre las dos potencias, Francia y Alemania.

54. Francastel, P., L'histoire de l'art instrument..., pág. 46. 
On heurtera sans doute, sur ces points, deux groupes de lecteurs. En France même, beaucoup railleront - du moins parmi les érudits - les prétentions d'un historien de l'art. C'est une tendance très répandue que de considérer cette discipline comme une chose de luxe, sans grande valeur méthodique ni pratique. On a pris chez nous l'habitude d'opposer, parmi les enseignements universitaires, ceux qui sont fondés sur une science - la philologie, l'histoire, la géographie - et ceux qui sont fondés sur des connaissances dites subjectives : l'histoire de l'art, celle de la musique, voire celle de la littérature. C'est une attitude peu scientifique, cependant, que de prétendre introduire une discrimination de principe entre les faits suivant leur origine ou leur nature. L'apparition des cathédrales ou la transformation de Florence au quattrocento constituent un ordre de faits aussi précis et aussi significatifs que l'organisation administrative et judiciaire de la France monarchique ou que les courants économiques du monde contemporain.

Je ne pense pas que personne puisse sérieusement soutenir que l'histoire des institutions ou l'histoire économique apportent des certitudes définitives et qu'elles échappent à la loi générale qui pèse sur toute science : l'impossibilité de rassembler la totalité des faits. Les philologues n'ont sans doute pas la naiveté de penser qu'ils détiennent des vérités premières - en vertu de quelque privilège extra-scientifique. Toute science est conjecture parce qu'elle détermine arbitrairement et la matière de son enquête - la notion même de fait - et sa méthode d'interprétation. La science consiste justement dans la définition forcément limitée des points de vue et dans l'objectivité des interprétations.

Les Allemands ne manqueront pas de dire, de leur côté que les points de vue d'un Français sont aussi suspects de parti pris et de chauvinisme que les leurs. Je n'ignore pas ta difficulté. Je ne suis pas assez naif pour croire que les Français disposent, à l'exclusion de toute autre nation, de la

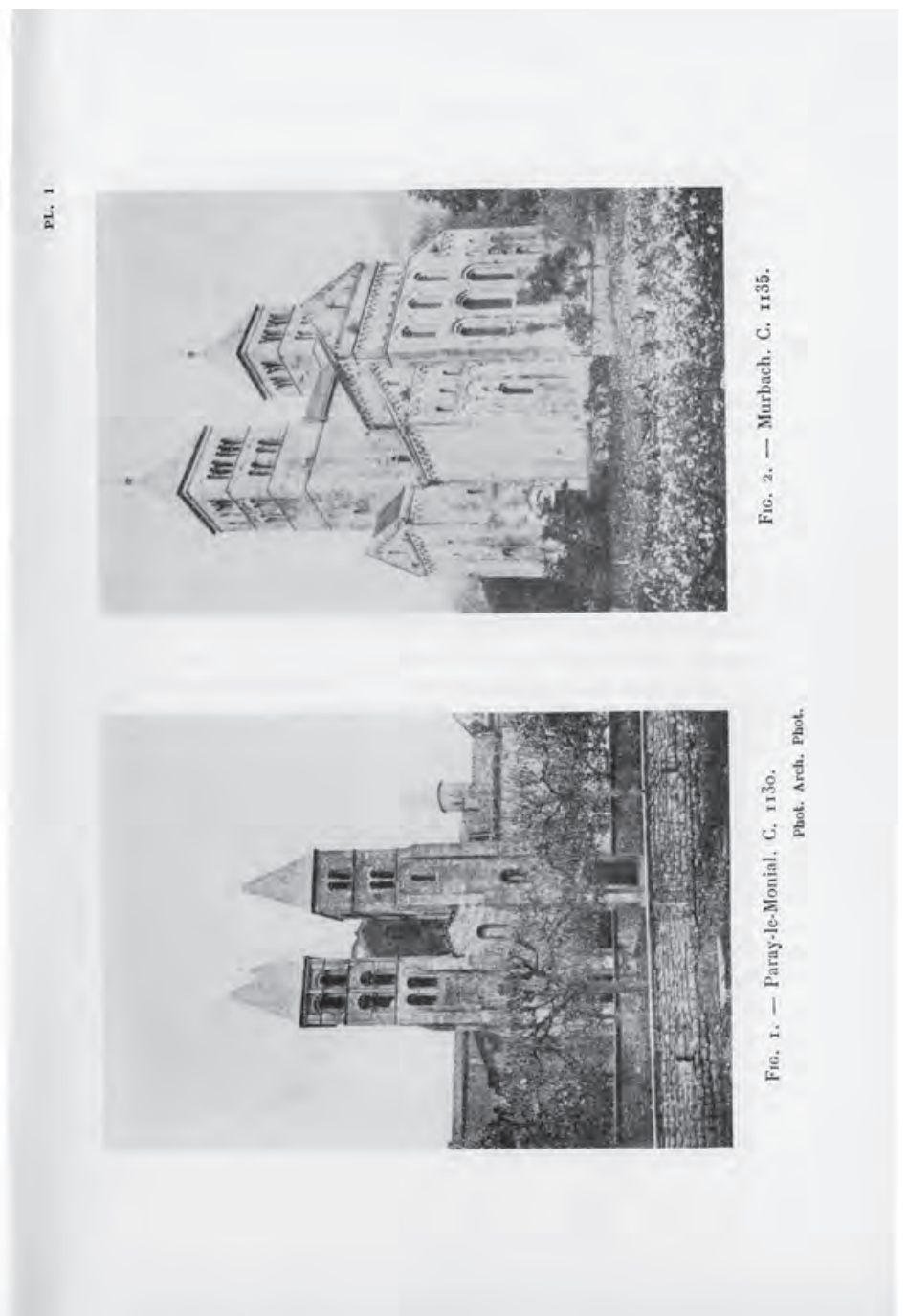

co y metodológico. El mismo autor describió detalladamente las dos vías de investigación que hasta la fecha se habían dado en el estudio de la formación y origen del arte gótico: la vía francesa, con Henri Focillon y Émile Mâle como referencias clave situando su origen en el abandono del arco antiguo en favor del arco apuntado; y la vía alemana, cuyos autores no contemplaban que un elemento tan corpóreo como el arco apuntado fuese esencia y punto de partida del gótico, sino que consideraban que su nacimiento se encontraba en una nueva forma de entender y relacionarse con el espacio. ${ }^{55}$ Su visión, aunque parcial, sitúa el interés en un aspecto novedoso y diferente: la historia del arte como disciplina, una disciplina que, sin embargo, no tiene su razón en la evolución de las formas.
11. Pierre Francastel Frontières du gothique. París: Mouton, 1970 [1945], pág. 16 y lám. 1.

55. Francastel, P., L’humanisme roman. París: Mouton, 1970 [1942], págs. 212-213. Esta visión de Francastel es también apoyada, aunque matizada, por Jorge Romero Brest, quien argumenta que los alemanes aceptaron que el sistema constructivo gótico se originó fuera de Alemania pero creen que fue allí, sin embargo, donde maduró según una visión espacial propia. Véase Romero Brest, J., «Courajod y el problema de los orígenes...», pág. 30. 


\section{LA POSGUERRA COMO GÉNESIS DE UNA IDENTIDAD ARTÍSTICA EUROPEA}

Después de la fatídica primera mitad del siglo xx, la intención común era la de unificar los pueblos europeos, ya fuese con medidas políticas y económicas ${ }^{56}$ o culturales. Superando los anteriores debates fragmentarios, la cultura se descubría como una posible herramienta de unión entre los pueblos y su historia, y el debate medieval siguió adelante con un espíritu conciliador y novedades respecto a la metodología. Esta se podría entender como una apertura de los marcos teóricos del gótico, una cuestión que no había existido hasta la fecha y que se debió, en parte, a que los autores activos a partir de la segunda mitad del siglo xx empezaron a incorporar a la historia del arte disciplinas de otros ámbitos. Ya no se podía plantear la historia del arte como una disciplina que girase en torno a lo objetual, como había sugerido el propio Francastel, sino como resultado de procesos más complejos y reflejo de realidades y condiciones muy diversas. En favor del enriquecimiento de la historia del arte y las humanidades se empezó, por fin, a dejar a un lado las teorías basadas en analogías formales, superficiales o casuales.

Ejemplo de ello, entre otros muchos, fue el historiador alemán Hans Jantzen, quien planteó lo gótico de forma muy diferente a como se había hecho en el periodo de entreguerras. En su monografía sobre arquitectura gótica publicado en 1957, Jantzen no solo desatendió la cuestión de la reivindicación alemana sino que afirmó la procedencia francesa y, en un acto de reconciliación histórica, alabó el inmaculado espíritu de las construcciones medievales capaces de hermanar a los pueblos de Europa a pesar de las guerras. ${ }^{57}$

En cualquier caso, fueron un historiador alemán emigrado a Estados Unidos, Erwin Panofsky, y uno francés, Georges Duby, los que en los años de posguerra plantearon análisis que abandonaban absolutamente las concepciones identitarias del arte gótico. Formado en el seno de una familia judía de la Berlín prenazi, Erwin Panofsky, después de que Heinrich Wölfflin hubiese publicado una interpretación del artista, ${ }^{58}$ presentó, en 1914, su reconocida y reivindicativa tesis doctoral sobre Albert Dürer, Dürers Kunsttheorie: vornehmlich in ihrem Verhaltnis zur Kunsttheorie der Italiener, ${ }^{59}$ trabajo que creía le podía servir de salvoconducto

56. Por ejemplo, la Unión Europea tuvo su primer momento fundacional a raíz del Tratado de París de 1951 y un año después se constituía el Parlamento Europeo. La creación de la Comunidad Económica Europea, sin embargo, se realizó más tarde, después del Tratado de Roma, en 1957. Una de sus consecuencias más manifiestas fue el establecimiento de la moneda única, el euro, en circulación desde 2002.

57. «Como fenómeno histórico, el arte gótico se difunde a partir de su lugar de origen, el norte de Francia, hasta convertirse en el estilo sagrado de toda Europa, aunque adoptando distintos matices según las condiciones que ofrecían los diversos pueblos y países de Occidente. [...] Aún se mantienen en pie en todos los países de Europa, a pesar de guerras y de revoluciones, de movimientos de reforma, conversiones y luchas religiosas, innumerables ejemplos de catedrales, iglesias y monasterios góticos en los que continúa celebrándose el servicio divino. [...] Después de las investigaciones sobre la historia de la arquitectura realizadas en el siglo XIX, ya no hay dudas sobre el lugar donde apareció el gótico occidental. Fue en las regiones del norte de Francia, alrededor de París - Île-de-France, Champagne, Picardía—, donde, en la segunda mitad del siglo XII, surgieron los conceptos decisivos que plasmarían el arte gótico», JANTZEN, H., La arquitectura gótica. Buenos Aires: Nueva Visión, 1959 [1957], págs. 7 y ss. Al final de la publicación, en el apartado llamado «Nota enciclopédica», desarrolla la cuestión del debate acerca de lo gótico y atribuye su comienzo a una necesidad del siglo xx que se desarrolla por dos vías, la centrada en cuestiones espirituales, por parte alemana —vinculándola al espíritu del romanticismo—, y la centrada en cuestiones estéticas, por parte francesa; ibidem, pág. 189.

58. Wölfflin, H., Die Kunst Albrecht Dürers. Múnich: Verlagsanstalt F. Bruckmann. A.-G., 1905.

59. La tesis, defendida en 1914, se publicó inmediatamente en Berlín: PANOFsKy, E., Die Theoretische Kunstlehre Albrecht Dürers. Berlín: Georg Reimer, 1914. Con esta obra Panofsky, que en su introducción reconocía que el estilo gótico fue creación de Francia al igual que el renacentista y el barroco lo fue de Italia, ofrecía a la sociedad alemana, que no había dado al mundo ninguno de esos estilos universalmente aceptados, un artista con el que identificarse nacionalmente y que a su vez fuese equiparable a otros genios como los que, por ejemplo, tenía Italia con Miguel Ángel o Rafael. Artista que perdió su popularidad y dejó de tener seguidores no por haber quedado anticuado, sino por haber traspasado los límites de la comprensión de sus contemporáneos. Su director fue Wilhelm Vöge, notable historiador del arte del periodo de fin de siglo que concentró sus esfuerzos en el arte medieval, especialmente en la psicología de la forma medieval. Fue docente en la Universidad de Estrasburgo, la de Friburgo y también trabajó en el departamento de escultura de los museos estatales de Berlín. 
en la situación política que se precipitaba. Pese a semejante aportación no pudo evitar el exilio y en 1933 emigró a Estados Unidos. Este exilio significó un cambio teórico en el análisis de lo medieval, que tuvo su fruto en la sesión pronunciada en las Wimmer Lectures de la Universidad de Harvard en $1948 .^{60}$ En ella, dejando al margen su afiliación a la hipótesis francesa sobre el origen gótico, Panofsky se interesó por investigar la estructura interna que provocó semejante desarrollo artístico, encontrándola, según su hipótesis, en la estructura mental del pensamiento escolástico. Un ejercicio, el de trasladar una estructura mental concreta sobre una estructura visual, que Pierre Bourdieu matizó al realizar la traducción francesa en 1967. Según Bourdieu, la teoría intuicionista de Panofsky sobre la afinidad estructural entre diferentes aspectos surgió de la necesidad de construir relaciones de consecuencia entre el arte y su realidad exterior. Es decir, una hipótesis sustentada en fenómenos, funciones y significaciones simbólicas más que en pruebas científicas considerables. Según Bourdieu, la formación del gótico trascendería lo escolástico como contenido pero podría responder a lo escolástico como actividad histórica, en el sentido de que a cada arte le corresponde un pensamiento estructural del mundo. ${ }^{61}$

Con Georges Duby y su Temps des cathédrales, ${ }^{62}$ la aproximación al nacimiento del arte gótico vuelve a presenciar un cambio de enfoque y se presenta como resultado de una estructura social determinada. Tanto lo cree así que los tres capítulos en los que se divide la obra —el monasterio, la catedral y el palacio - se desarrollan a partir de la exposición de las tres presencias humanas que habitan en él, siendo Dios la presencia catedralicia. ${ }^{63}$ Una valoración típica de la antropología donde las estructuras parentales, los linajes y los otros modelos culturales presentes en la vida cotidiana tienen un papel esencial en las expresiones y actividades de los individuos.

La capitulación sin condiciones que Alemania firmó en el Cuartel General Supremo de la Fuerza Expedicionaria Aliada (SHAEF) de Reims en la madrugada del 7 de mayo de $1945^{64}$ propició la clausura simbólica de los conflictos bélicos de la Primera y la Segunda Guerra Mundial. Igualmente, en clave académica, este hecho supuso la renovación de los marcos teóricos sostenedores del estudio del arte gótico y, en general, de todas las manifestaciones artísticas. Aún más, contribuyó a una nueva utilización identitaria de lo gótico paralela a los iniciales intentos, por aquel entonces económicos, de propiciar la integración y gobernanza en común de los Estados y pueblos de Europa. La cultura y el arte se descubrían como una posible herramienta de

Sobre Vöge véase SAUERLÄNDER, W., «Wilhelm Vöge und die Anfänge der kunstgeschichtlichen Lehre in Freiburg», Zeitschrift für Kunstgeschichte, LXI, 1998, págs. 156-165.

6o. PAnofsky, E., Architecture gothique et pensée scolastique. París: Éditions du Minuit, 1967 [1948]. El texto es la publicación de la conferencia anteriormente citada y editada en inglés como Gothic Architecture and Scholasticism. Latrobe: The Archabbey Press, 1951.

61. «Pour donner à cette analyse toute sa portée [...] il faut observer d'abord que les schèmes qui organisent la pensée des hommes cultivés dans les sociétés dotées d'une institution scolaire (par exemple, les principes d'organisation du discours que les traités de rhétorique nommaient figures de mots et figures de pensée) remplissent sans doute la même fonction que les schèmes inconscients que l'ethnologue découvre, par l'analyse de créations telles que rites ou mythes, chez les individus des sociétés dépourvues de ces institutions, la même fonction que ces "formes primitives de classification", pour parler le langage de Durkheim et de Mauss, qui ne sauraient faire objet d'une saisie consciente et d'une transmission explicite et méthodique», BouRDIEU, P., «Postface», en Panofsky, E., Architecture gothique et pensée..., pág. 151.

62. Duby, G., Le Temps des cathédrales. L'art et la société 980-1420. París: Gallimard, 1976. La versión inicial de esta obra se publicó en tres tomos: Adolescence de la chrétienté occidentale, 980-1140; L'Europe des Cathédrales, 1140-1280 y Fondements d'un Nouvel humanisme, 1280-1440. Ginebra: Skira, 1966-1967.

63. "Au milieu de la création, au milieu de l'iconographie des cathédrales s'établit donc la figure de l'homme. L'homme gothique est lui aussi un type. [...] L'homme gothique, cependant, est aussi une personne. A Reims - parmi les saints, les apôtres, près de la Vierge et non loin de Jésus qui lui ressemble - paraît dans son humilité la Servante de la Présentation. Une personne libre, responsable de ces actes. Une conscience. La chrétienté du XIII ${ }^{e}$ siècle, qui apprend à se confesser tous les ans, à s'interroger, à découvrir les intentions de ses fautes, s'exerce à cette introspection que déjà proposait Abélard», DuBY, G., Le Temps des cathédrales..., págs. 182-183.

64. El segundo acto de la capitulación tuvo lugar un día después en Berlín por parte de funcionarios alemanes, liderados por Wilhelm Keitel, ante los mandos soviéticos. 
unión entre los pueblos del territorio euro-

\section{L'Europe Gothique XII ${ }^{\mathrm{e}} \mathrm{XIV}^{\mathrm{e}}$ siècles}

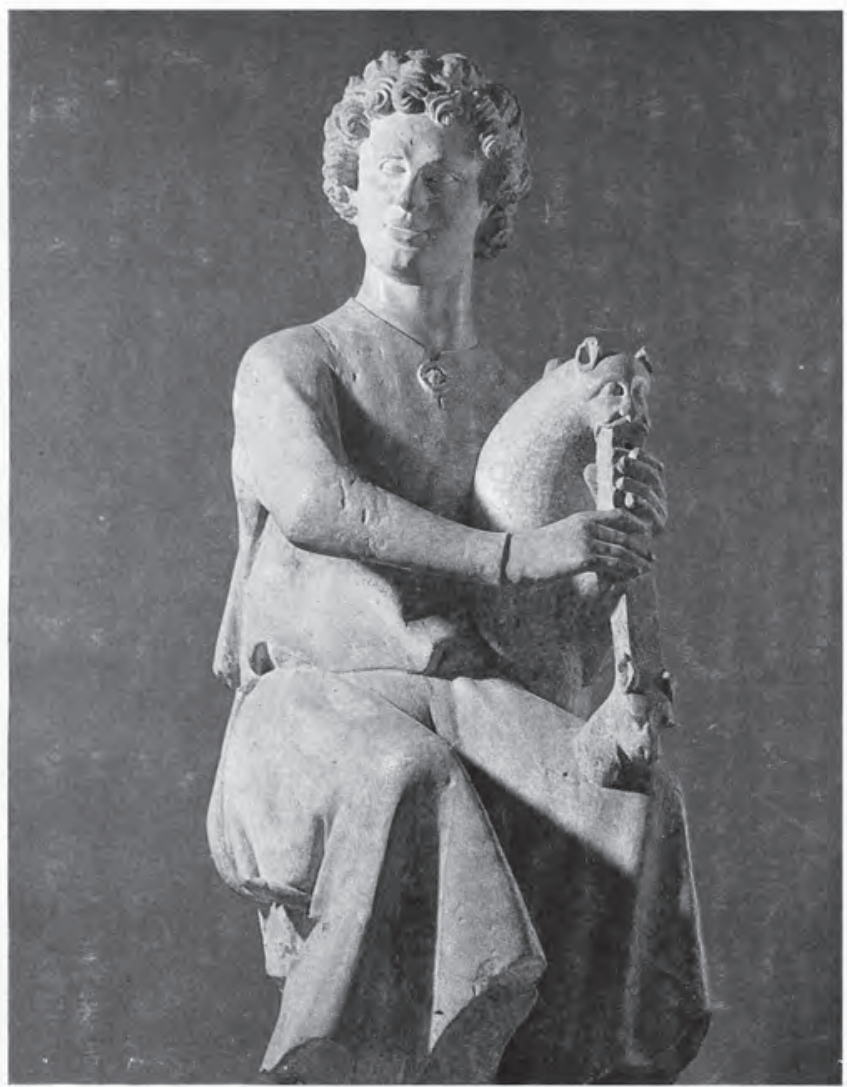

peo. Signo de ello fueron las exposiciones organizadas por el Consejo de Europa desde $1954^{65} \mathrm{y}$, entre ellas, la duodécima exposición que bajo el título de L'Europe Gothique XII ${ }^{e}$ $X I V^{e}$ siècles $^{66}$ se celebró en París en 1968 (ilustración 12). El texto de introducción del comisario alemán -la muestra estaba dividida según los diferentes centros geográficos: el mundo anglosajón, el germánico, la península ibérica, los países escandinavos y los Países Bajos- cerraba definitivamente las heridas abiertas por los conflictos bélicos y evidenciaba de manera rotunda la aceptación de la comunidad académica del origen francés del gótico. ${ }^{67}$ Con este gesto la organización promotora de la exposición conseguía documentar, a través de las artes figurativas, los momentos que han contribuido a conformar la identidad europea, entre ellos, y especialmente, el gótico. ${ }^{68}$

Vers 1130, dans la région parisienne, on commença d'édifier des églises d'une architecture si nouvelle qu'il faut employer à son propos, non pas le mot d'«évolution» mais celui de «mutation». Ce fut l'un des événements les plus importants de l'histoire de la civilisation occidentale depuis la chute de l'Empire romain jusqu'aux temps modernes. L'archéologie ayant eu longtemps pour mé-

12. L'Europe Gothique, XII $X I V^{e}$ siècles, catálogo de la exposición, Pavillon de Flore, Musée du Louvre. París: Réunion des Musées nationaux, 1968 portada. thode essentielle l'étude comparée et raisonnée des formes auxquelles on prêtait la croissance régulière des plantes, la naissance de l'art gothique fut d'abord considérée comme un véritable

5. La primera, celebrada en Bruselas (1954-1955), fue dedicada al humanismo; la segunda, en Ámsterdam (1955), presentó el triunfo del manierismo de Miguel Ángel a El Greco; la tercera, acogida por Roma (1956-1957), estuvo dedicada al realismo, clasicismo y barroco del siglo XVII; la cuarta, exhibida en Múnich (1958), presentó al arte rococó; la quinta, que tuvo lugar en Londres (1959), se centró en el movimiento romántico; la sexta, organizada en París, analizó las fuentes del arte europeo del siglo xx, y la séptima, con el tema del arte románico, tuvo sus sedes en Barcelona y en Santiago de Compostela. Hasta 2017, la última de las celebradas, la trigésima, se presentó en 2014 en Berlín, Tallin, Milán y Cracovia con la temática del deseo de libertad.

66. Pradel, P. (comis.), L'Europe Gothique, XII XIV siècles, douzième exposition européenne d'art organisé à l'initiative et sous les auspices du Conseil de l'Europe, cat. exp., 2 de abril - 1 de julio de 1968, Pavillon de Flore, Musée du Louvre, París. París: Réunion des Musées nationaux, 1968.

67. «La transformation de la sculpture monumentale en fonction d'une architecture nouvelle est la caractéristique essentielle des premières sculptures gothiques des terres d'Empire. Ce changement ne fut possible que grâce aux exemples donnés par l'art français»: STEINGRÄBER, E., «L'art gothique dans les pays germaniques», en: PrADEL, P. (comis), L'Europe Gothique..., pág. 39.

68. Diecisiete años después de que concluyera la Segunda Guerra Mundial, el 8 de julio de 1962, Charles de Gaulle y Konrad Adenauer celebraron en la catedral de Reims una misa de reconciliación francogermana que anticipó la firma del Tratado del Elíseo (22 de enero de 1963), en el que se establecieron unas bases nuevas para las relaciones entre ambos países, tantas veces afectadas por guerras durante la historia (ilustración 13). El tratado constituyó con el tiempo el fundamento de una intensa cooperación bilateral en los campos de la política, la economía, la cultura y la sociedad, e igualmente para la integración europea. Cincuenta años después, el 8 de julio de 2012, el presidente francés, François Hollande, y la canciller alemana, Angela Merkel, celebraron de nuevo un encuentro ante la catedral de Reims, como símbolo de la reconciliación francoalemana. El acto conmemorativo del 50. ${ }^{\circ}$ aniversario de la firma del Tratado del Elíseo se celebró el 22 de enero de 2013 en el Reichstag de Berlín. 


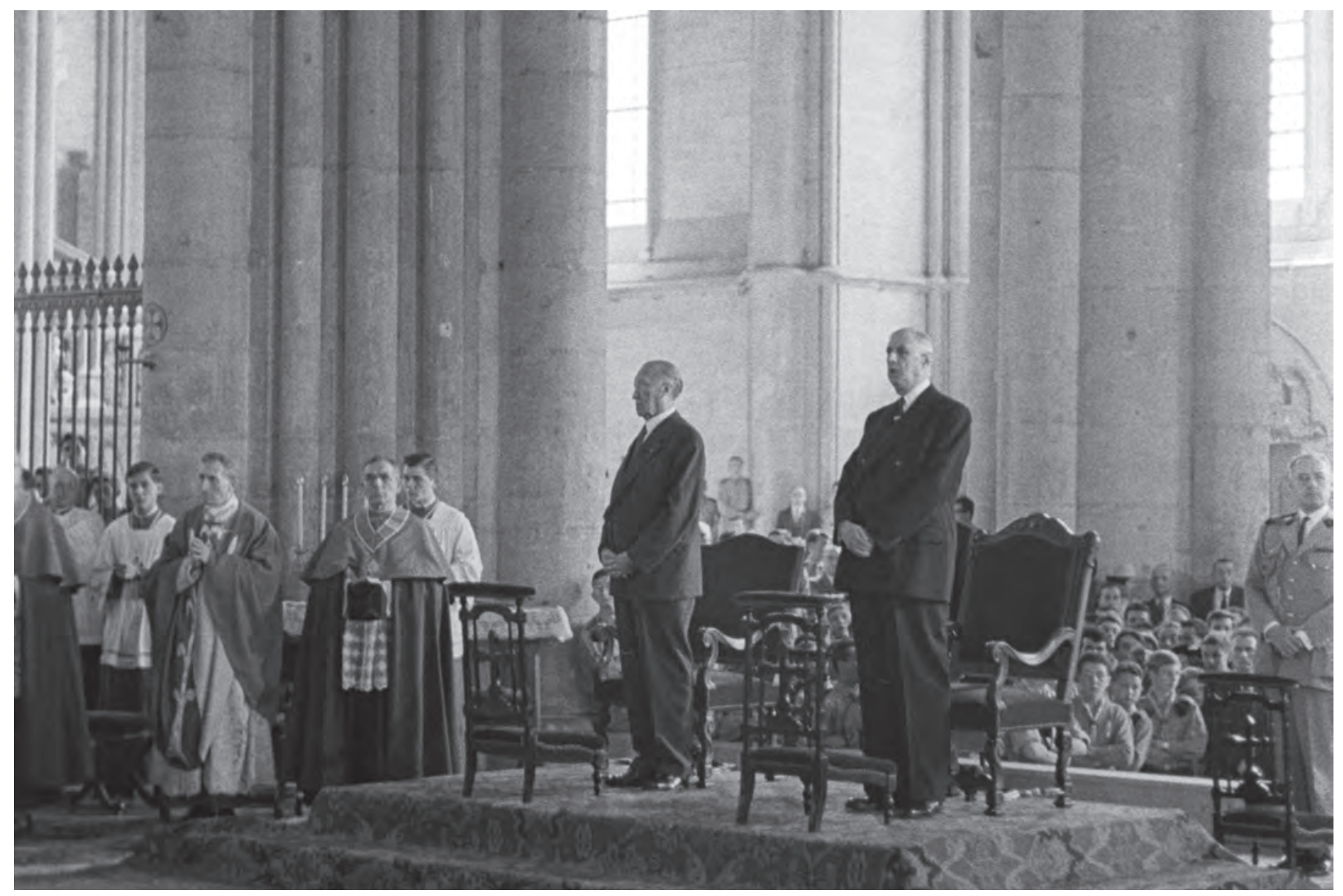

miracle que l'on associait au rayonnement de la dynastie capétienne. Il s'en faut de beaucoup que l'on sache tout, aujourd'hui, de cette merveilleuse histoire. Les recherches et les découvertes faites au cours de ces dernières années - et il faut placer au tout premier rang celles de Marcel Aubertpermettent cependant d'en retracer les étapes et d'en suggérer les raisons. En réalité, ce que l'on a appelé le «miracle français» du $\mathrm{x}^{\mathrm{e}}$ siècle a été préparé non seulement par la Gaule carolingienne et la France romane, mais par des recherches poursuivies dans toute l'Europe durant plusieurs générations. $^{69}$

13. Egon Steiner [Konrad

Adenauer

(izquierda)

y Charles de

Gaulle (derecha)

asistiendo

a una misa

en la catedral de Reims el 8 de julio de 1962], 1962, fotografía Bundesarchiv, Koblenz.

69. Hubert, J., L'Europe Gothique, XII XIV siècles..., pág. XXVII. 